Supplementary Information for

\title{
Phytotoxic Neocassane Diterpenes from Eragrostis Plana
}

Ana Paula P. Klein Hendges, ${ }^{\dagger}$ Elaine Fernanda dos Santos, ${ }^{\dagger}$ Sirlei D. Teixeira, ${ }^{\dagger}$

Francielli S. Santana, ${ }^{\dagger}$ Michelangelo M. Trezzi, ${ }^{\S}$ Andrea N. L. Batista, ${ }^{\Perp}$ Joao M.

Batista Jr., ${ }^{\nabla}$ Vanderlei A. de Lima, ${ }^{\ddagger}$ Francisco de Assis Marques, ${ }^{\dagger}$ Beatriz H. L. N.

Sales Maia ${ }^{\dagger *}$

${ }^{\dagger}$ Department of Chemistry, Federal University of Parana, Av. Cel. Francisco H. dos Santos 100, Jardim das Americas, Curitiba PR 81530-900, Brazil

${ }^{\star}$ Department of Chemistry and ${ }^{\S}$ Department of Agrarian Sciences, Federal Technological University of Parana, Via do Conhecimento s/n, Km 01, Fraron, Pato Branco PR 85503-390, Brazil

"Department of Organic Chemistry, Chemistry Institute, Fluminense Federal University, Outeiro de Sao Joao Batista s/n, Niteroi RJ 24020-141, Brazil

${ }^{\nabla}$ Institute of Science and Technology, Federal University of Sao Paulo, Rua Talim ${ }^{\circ}$ 330, Sao Jose dos Campos SP 12231-280, Brazil

Corresponding Author:

*Tel.: +55 19 99215-8242. E-mail: bhsalesmaia@ gmail.com 


\section{Contents}

Table S1. Crystallographic and refinement data for Neocassa-12(13),15-dien-14-one (1) and Neocassa-

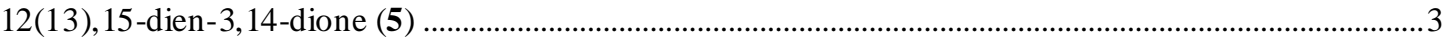

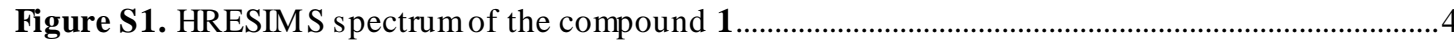

Figure S2. IR Spectru m of the compound 1

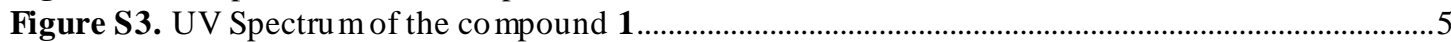

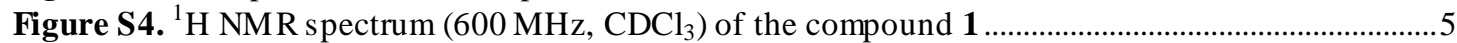

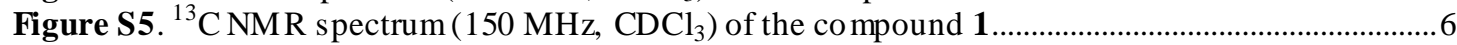

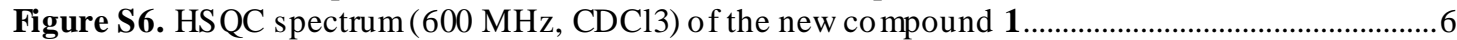

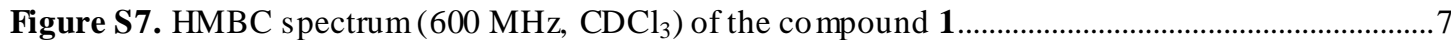

Figure S8. ${ }^{1} \mathrm{H}-{ }^{1} \mathrm{HCOSY}$ spectrum $\left(600 \mathrm{MHz}, \mathrm{CDCl}_{3}\right)$ of the co mpound 1 ..............................................

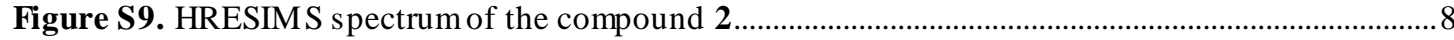

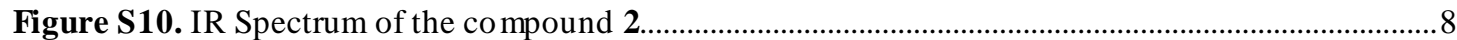

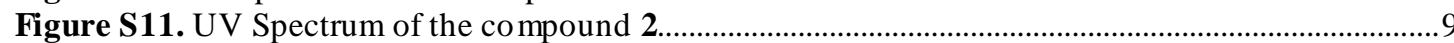

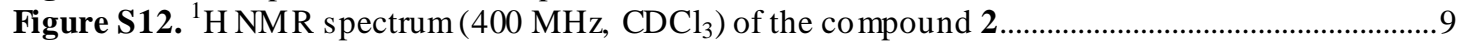

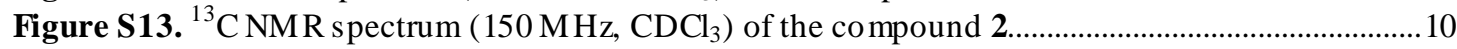

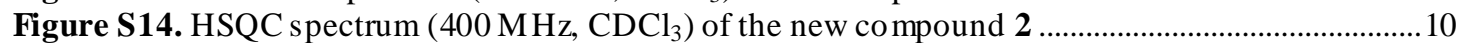

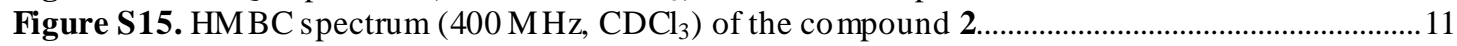

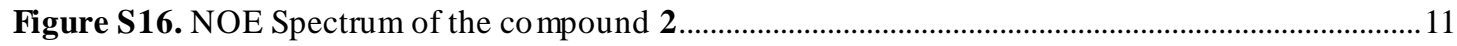

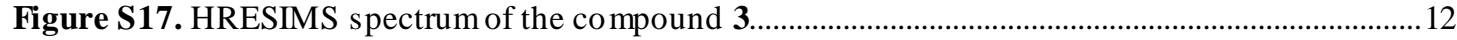

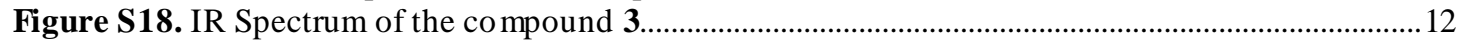

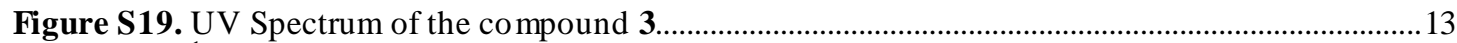

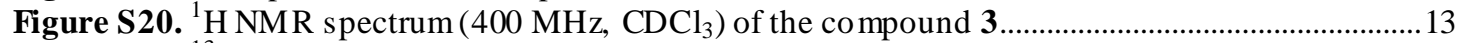

Figure S21. ${ }^{13} \mathrm{C}$ NMR spectrum $\left(150 \mathrm{MHz}, \mathrm{CDCl}_{3}\right)$ of the co mpound 3................................................. 14

Figure S22. HSQC spectrum ( $400 \mathrm{MHz}, \mathrm{CDCl}_{3}$ ) of the new co mpound 3 ..............................................14

Figure S23. $\mathrm{HMBC}$ s pectrum $\left(400 \mathrm{MHz}, \mathrm{CDCl}_{3}\right)$ of the co mpound 3................................................. 15

Figure S24. ${ }^{1} \mathrm{H}-{ }^{1} \mathrm{HCOSY}$ s pectrum $\left(400 \mathrm{MHz}, \mathrm{CDCl}_{3}\right)$ of the co mpound 3........................................15

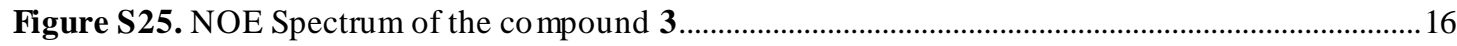

Figure S26. HRESIMS spectrum of the co mpound 4............................................................................ 16

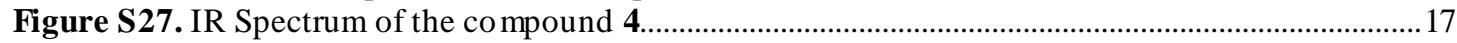

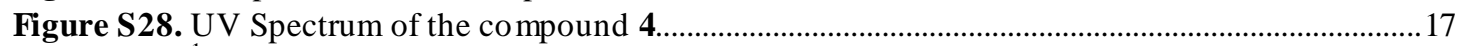

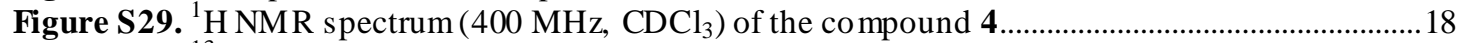

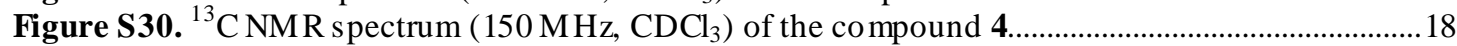

Figure S31. HSQC spectrum ( $400 \mathrm{MHz}, \mathrm{CDCl}_{3}$ ) of the new co mpound 4 …...........................................19

Figure S32. HMBC spectrum $\left(400 \mathrm{MHz}, \mathrm{CDCl}_{3}\right)$ of the co mpound 4 ..................................................19

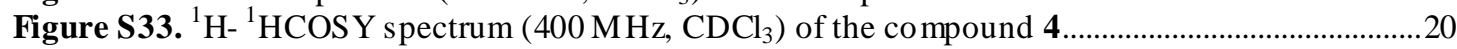

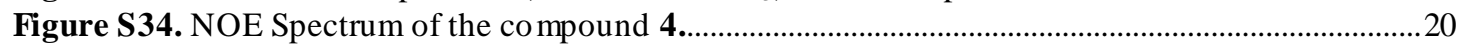

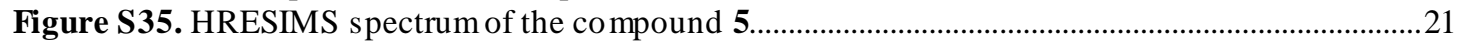

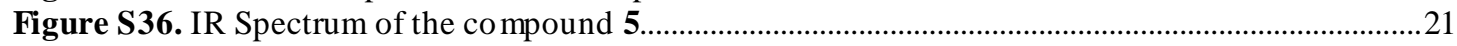

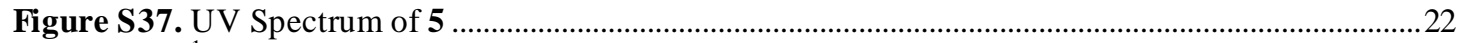

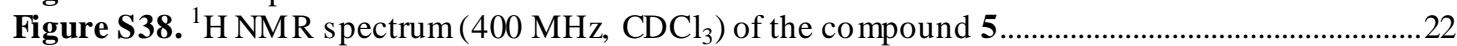

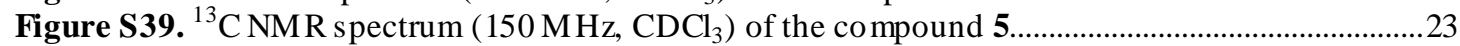

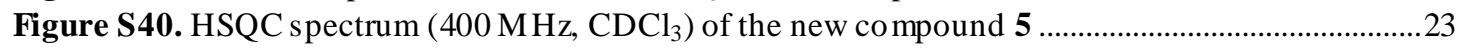

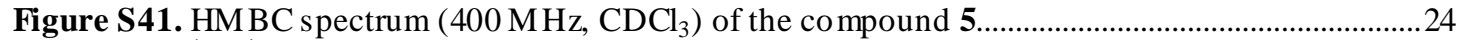

Figure S42. ${ }^{1} \mathrm{H}-{ }^{1} \mathrm{HCOSY}$ spectrum $\left(400 \mathrm{MHz} \mathrm{CDCl}_{3}\right)$ of the co mpound 5........................................2

Figure S43. NOE Spectrum of the co mpound 5 .................................................................................25

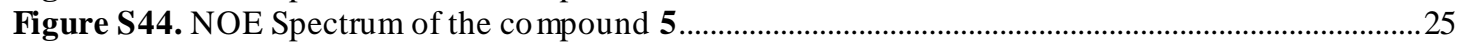

Figure S45. Optimized structures, relative energies, and Boltzmann populations of the lowest-energy

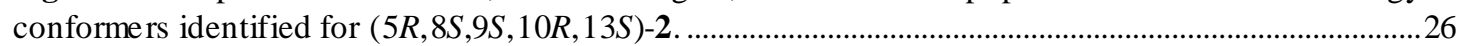

Figure S46. Optimized structures, relative energies, and Boltzmann populations of the lowest-energy

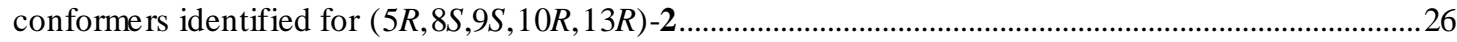

Figure S47. Experimental and calculated vibrational dis symmetry factor (VDF) spectra .......................27 
Table S1. Crystallographic and refinement data for Neocassa-12(13),15-dien-14-one

(1) and Neocassa-12(13),15-dien-3,14-dione (5)

\begin{tabular}{|c|c|c|}
\hline Crystal data & 1 & 5 \\
\hline Elemental formula & $\mathrm{C}_{20} \mathrm{H}_{30} \mathrm{O}$ & $\mathrm{C}_{20} \mathrm{H}_{28} \mathrm{O}_{2}$ \\
\hline Molar mass / $\mathrm{g} \mathrm{mol}^{-1}$ & 286.44 & 300.42 \\
\hline Temperature/ K & 299(2) & $288(2)$ \\
\hline Radiation type & Mo $K \alpha$ & $\operatorname{Mo} K \alpha$ \\
\hline Cry stal system, space group & Monoclinic, $\mathrm{P} 2_{1}$ & Orthorhombic, $\mathrm{P} 2{ }_{1} 2_{1} 2_{1}$ \\
\hline $\mathrm{a} / \mathrm{A}$ & $6.2593(14)$ & $6.4025(4)$ \\
\hline $\mathrm{b} / \mathrm{A}$ & $11.449(3)$ & $11.0913(7)$ \\
\hline c/ $/ \breve{A}$ & $12.078(3)$ & $23.6652(14)$ \\
\hline$\alpha /{ }^{\circ}$ & 90 & 90 \\
\hline$\beta /{ }^{\circ}$ & $98.210(5)$ & 90 \\
\hline$\gamma / \circ$ & 90 & 90 \\
\hline Volume / $\mathrm{A}^{3}$ & $856.6(3)$ & $1680.51(18)$ \\
\hline $\mathrm{Z}$ & 2 & 4 \\
\hline Density / $\mathrm{Mgm}^{-3}$ & 1.110 & 0.074 \\
\hline $\mathrm{F}(000)$ & 316 & 656 \\
\hline Absorption coefficient $/ \mathrm{mm}^{-1}$ & 0.066 & 0.074 \\
\hline Cry stal size / mm & $0.452 \times 0.415 \times 0.070$ & $0.314 \times 0.228 \times 0.116$ \\
\hline$\theta$ range $/^{\circ}$ & 3.3 to 24.5 & 3.2 to 26.0 \\
\hline Completeness / \% & 99.7 & 99.7 \\
\hline Absorption correction & $\begin{array}{l}\text { Semi-empirical from } \\
\text { equivalents }\end{array}$ & $\begin{array}{l}\text { Semi-empirical from } \\
\text { equivalents }\end{array}$ \\
\hline$T_{\max }, T_{\min }$ & $0.7455,0.6747$ & $0.7455,0.7057$ \\
\hline Reflection collected & 17626 & 74131 \\
\hline Unique data & $2850\left[\mathrm{R}_{\mathrm{int}}=0.048\right]$ & $3276\left[\mathrm{R}_{\mathrm{int}}=0.071\right]$ \\
\hline Observed data $[\mathrm{I}>2 \sigma(\mathrm{I})]$ & 2309 & 2731 \\
\hline Number of parameters / restraints & $195 / 1$ & $311 / 6$ \\
\hline Goodness of fit on $\mathrm{F}^{2}$ & 1.189 & 1.062 \\
\hline $\mathrm{R}[\mathrm{I}>2 \sigma(\mathrm{I})], \mathrm{R}_{w}$ & $\mathrm{R}=0.084, \mathrm{R}_{w}=0.278$ & $\mathrm{R}=0.041 \mathrm{R}_{w}=0.094$ \\
\hline $\mathrm{R}, \mathrm{R}_{w}$ (all data) & $\mathrm{R}=0.099, \mathrm{R}_{w}=0.290$ & $\mathrm{R}=0.055, \mathrm{R}_{w}=0.100$ \\
\hline Largest diff. peak and hole / e $\breve{A}^{-3}$ & 0.32 and -0.19 & 0.19 and -0.15 \\
\hline
\end{tabular}

$\mathrm{W}=\left[\sigma^{2}\left(\mathrm{Fo}^{2}\right)+(0.1920 * \mathrm{P})^{2}+0.1695 * \mathrm{P}\right]^{-1}$ where $\mathrm{P}=\left(\mathrm{Fo}^{2}+2 \mathrm{Fc}^{2}\right) / 3$ for $\mathbf{1}$.

$\mathrm{w}=\left[\sigma^{2}\left(\mathrm{Fo}^{2}\right)+(0.0511 * \mathrm{P})^{2}+0.2382 * \mathrm{P}\right]^{-1}$ where $\mathrm{P}=\left(\mathrm{Fo}^{2}+2 \mathrm{Fc}^{2}\right) / 3$ for 5 . 
Figure S1. HRESIMS spectrum of the compound 1

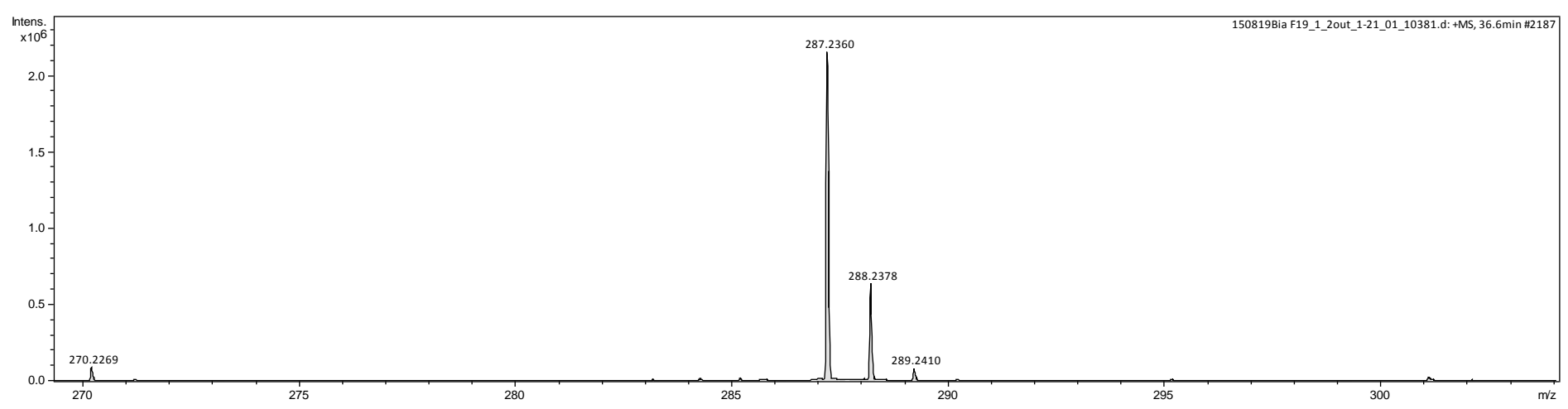

Figure S2. IR Spectrum of the compound 1

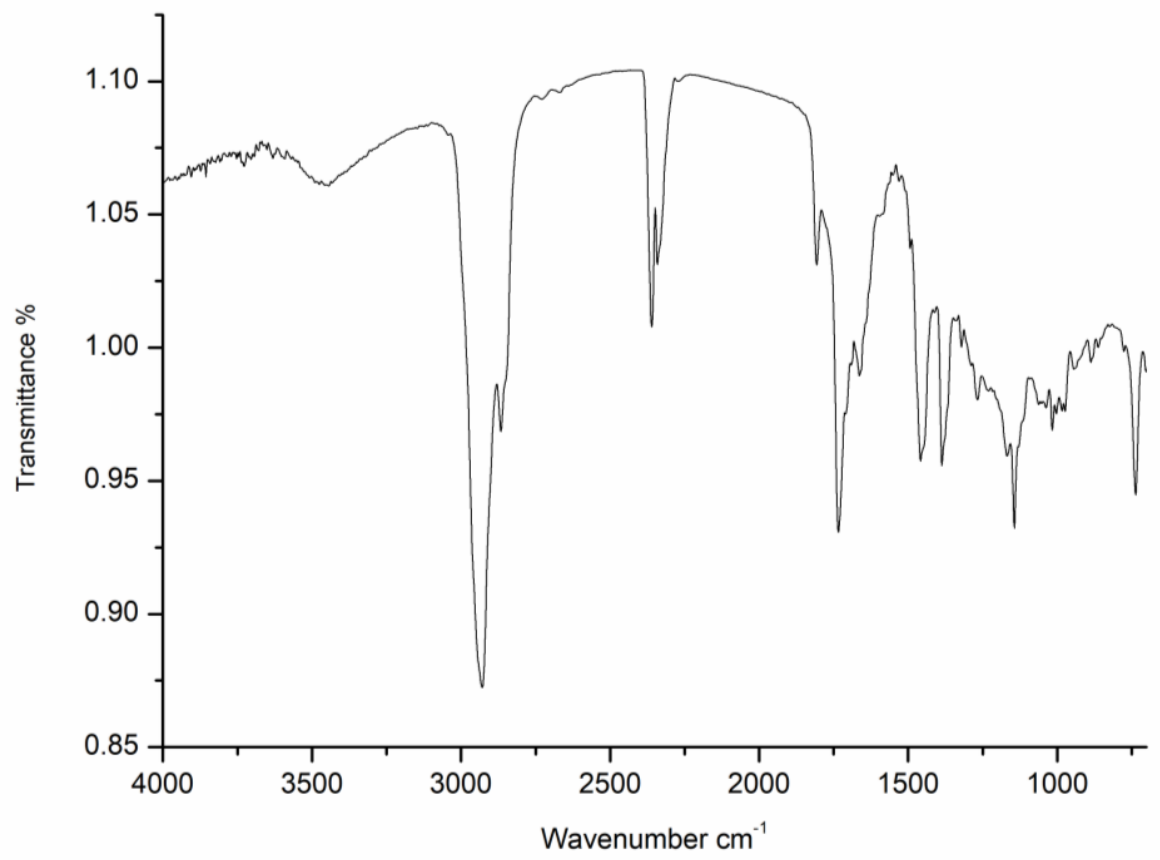


Figure S3. UV Spectrum of the compound 1

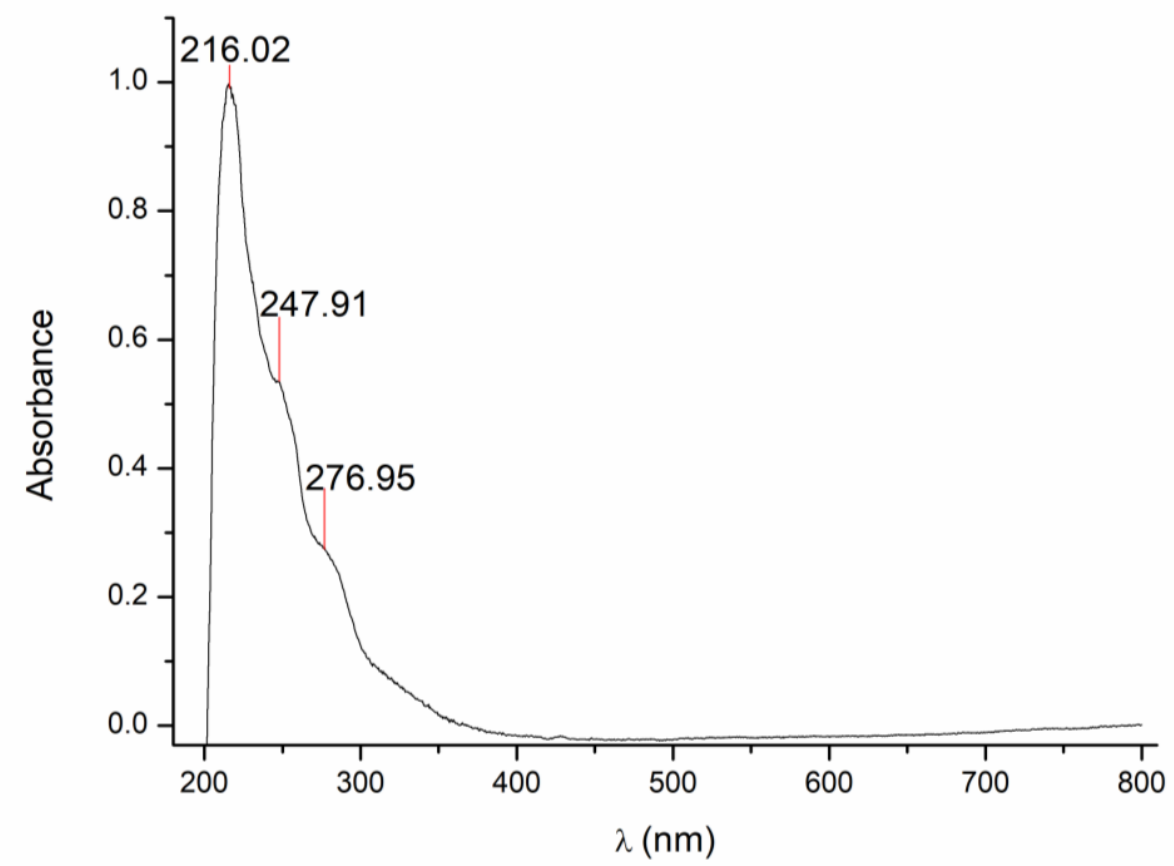

Figure S4. ${ }^{1} \mathrm{H}$ NMR spectrum $\left(600 \mathrm{MHz}, \mathrm{CDCl}_{3}\right)$ of the compound $\mathbf{1}$

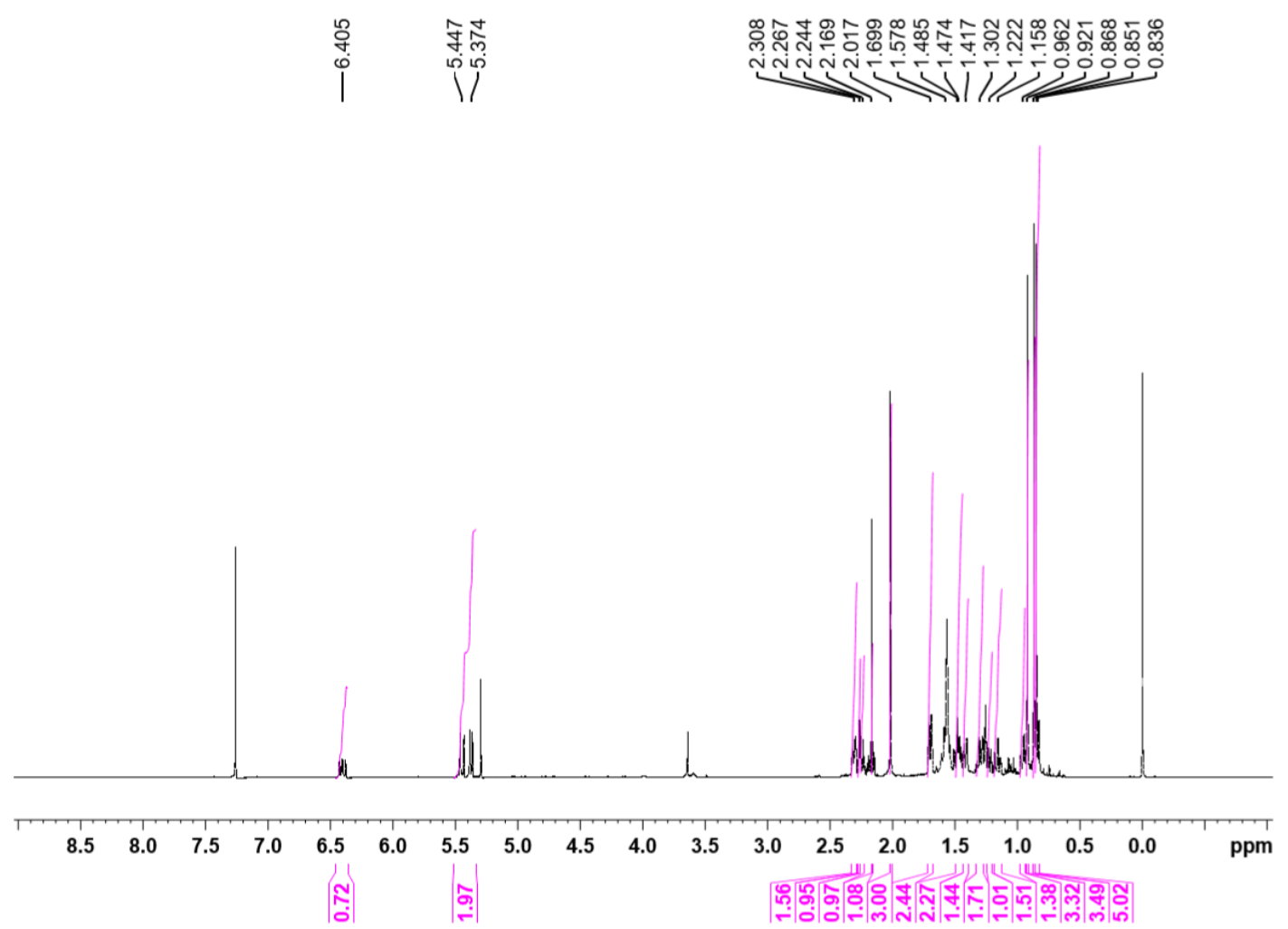


Figure S5. ${ }^{13} \mathrm{C}$ NMR spectrum $\left(150 \mathrm{MHz}, \mathrm{CDCl}_{3}\right)$ of the compound $\mathbf{1}$

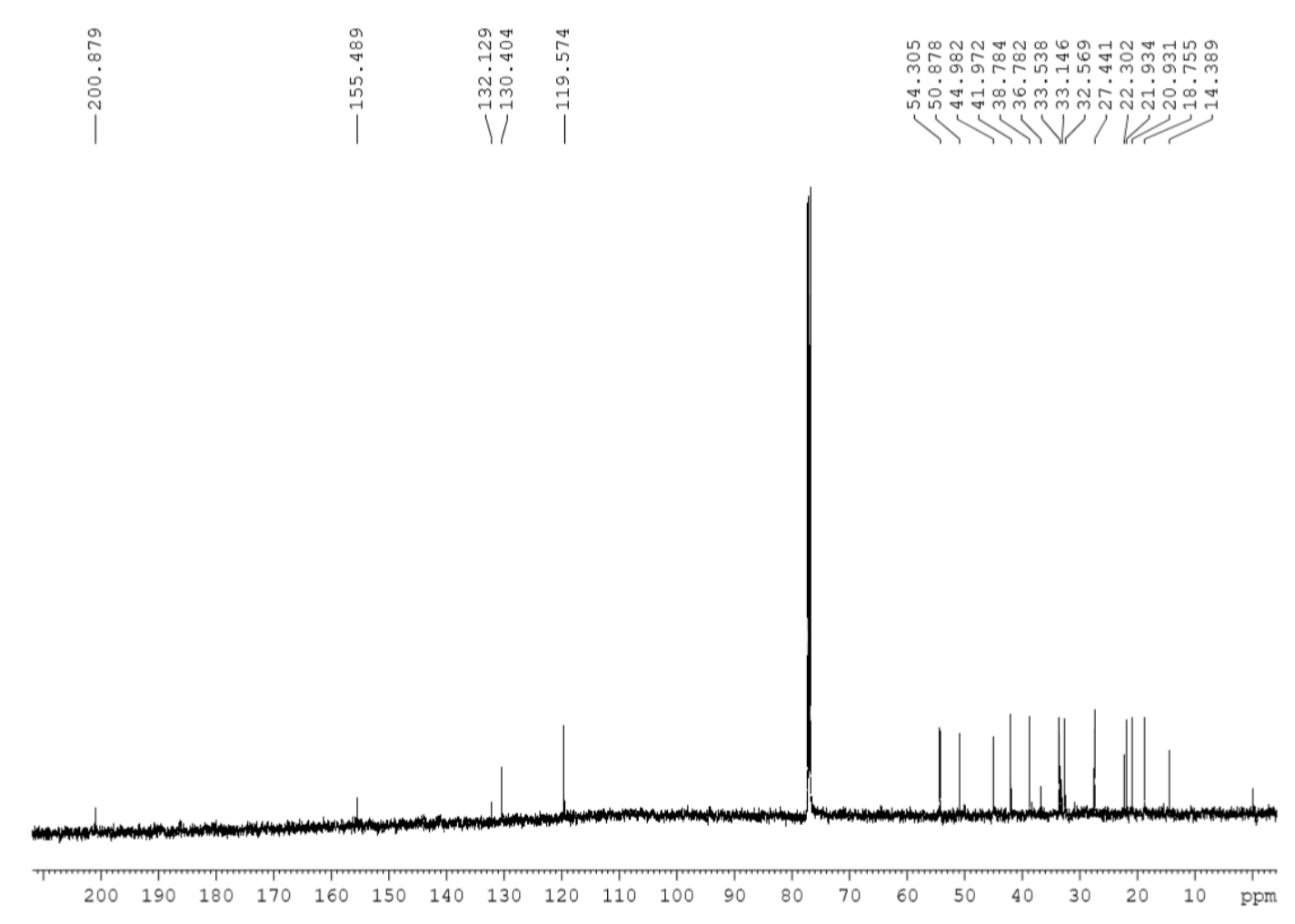

Figure S6. HSQC spectrum $(600 \mathrm{MHz}, \mathrm{CDCl})$ of the new compound $\mathbf{1}$

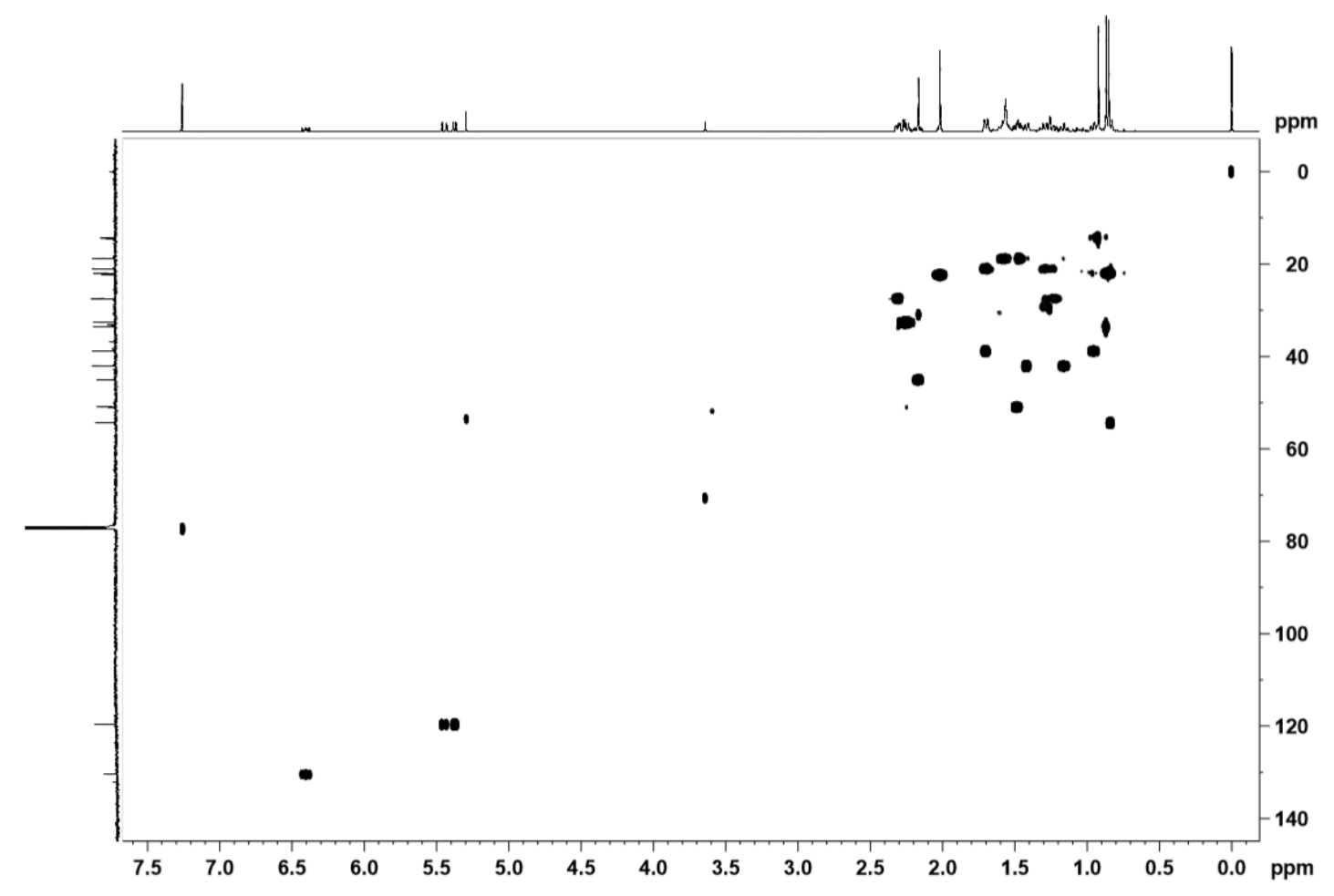


Figure S7. $\mathrm{HMBC}$ spectrum $\left(600 \mathrm{MHz}, \mathrm{CDCl}_{3}\right)$ of the compound $\mathbf{1}$

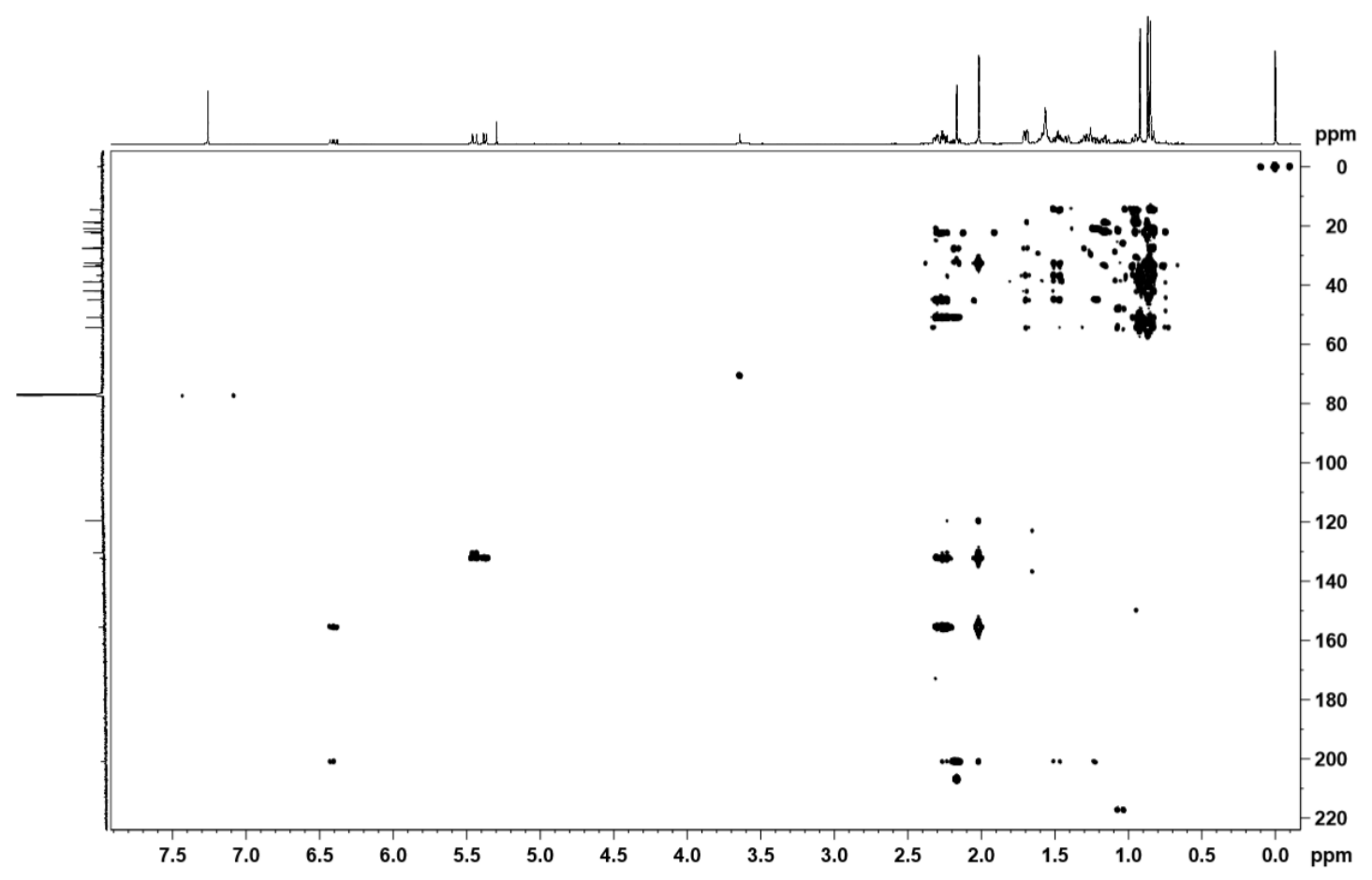

Figure S8. ${ }^{1} \mathrm{H}-{ }^{1} \mathrm{HCOSY}$ spectrum $\left(600 \mathrm{MHz}, \mathrm{CDCl}_{3}\right)$ of the compound $\mathbf{1}$

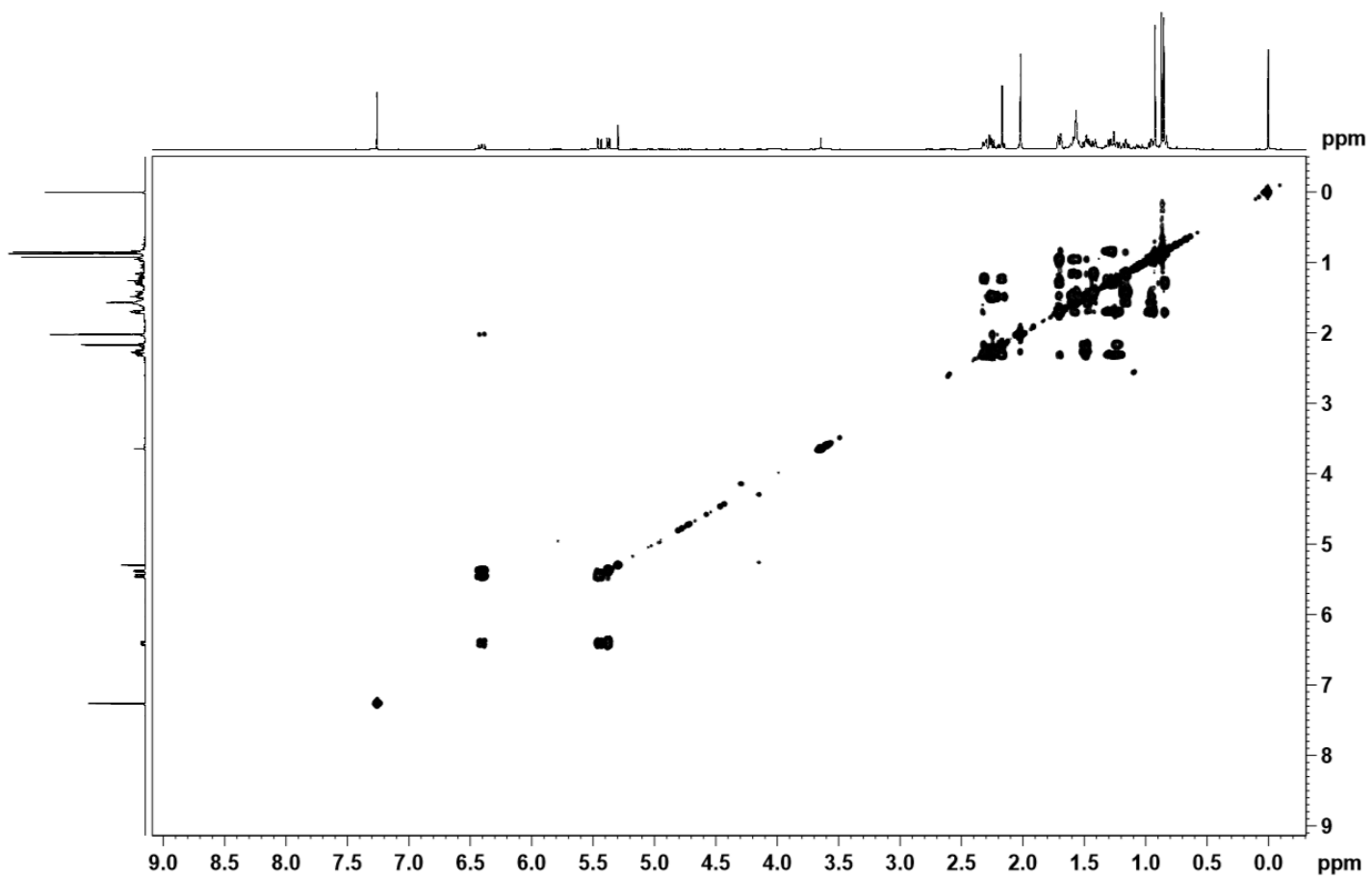


Figure S9. HRESIMS spectrum of the compound 2

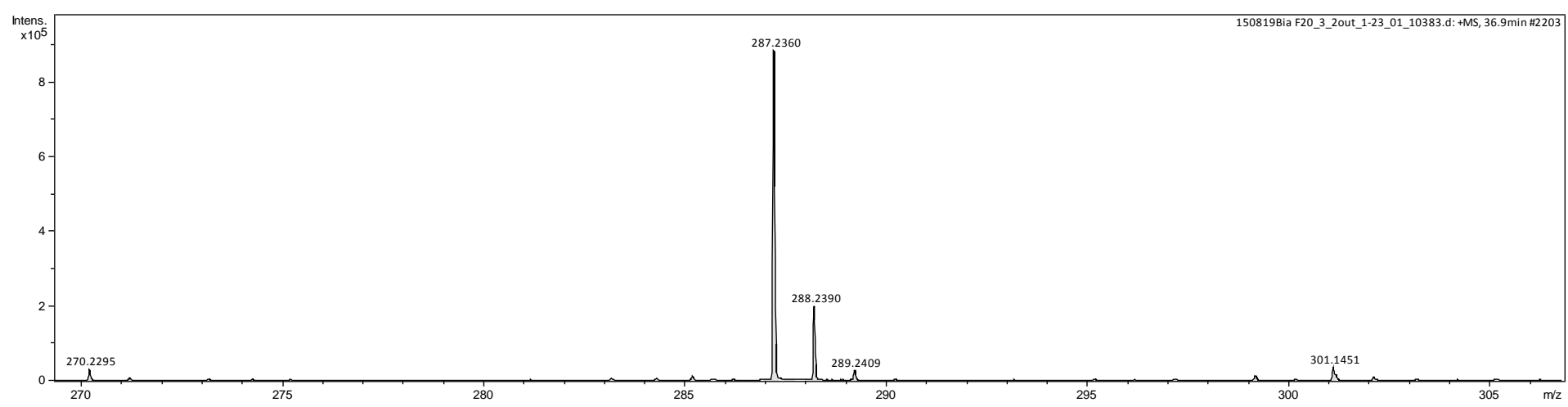

Figure S10. IR Spectrum of the compound 2

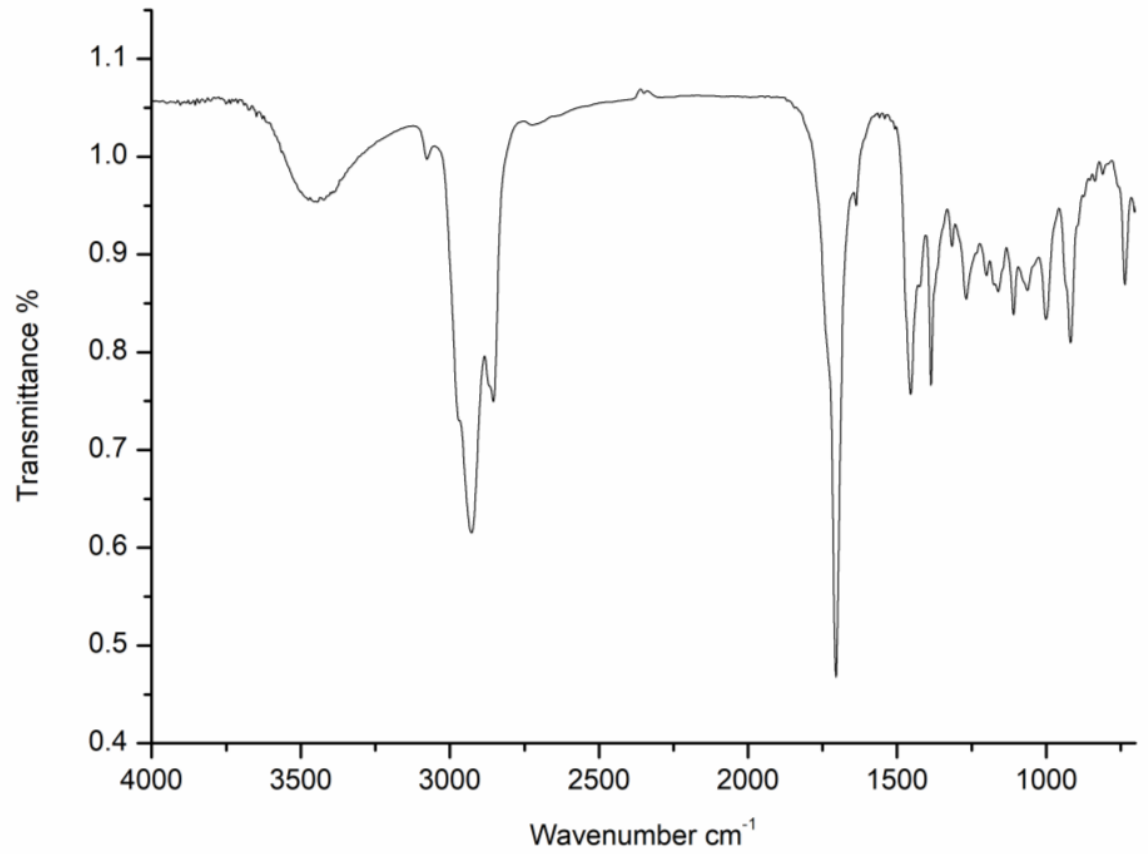


Figure S11. UV Spectrum of the compound 2

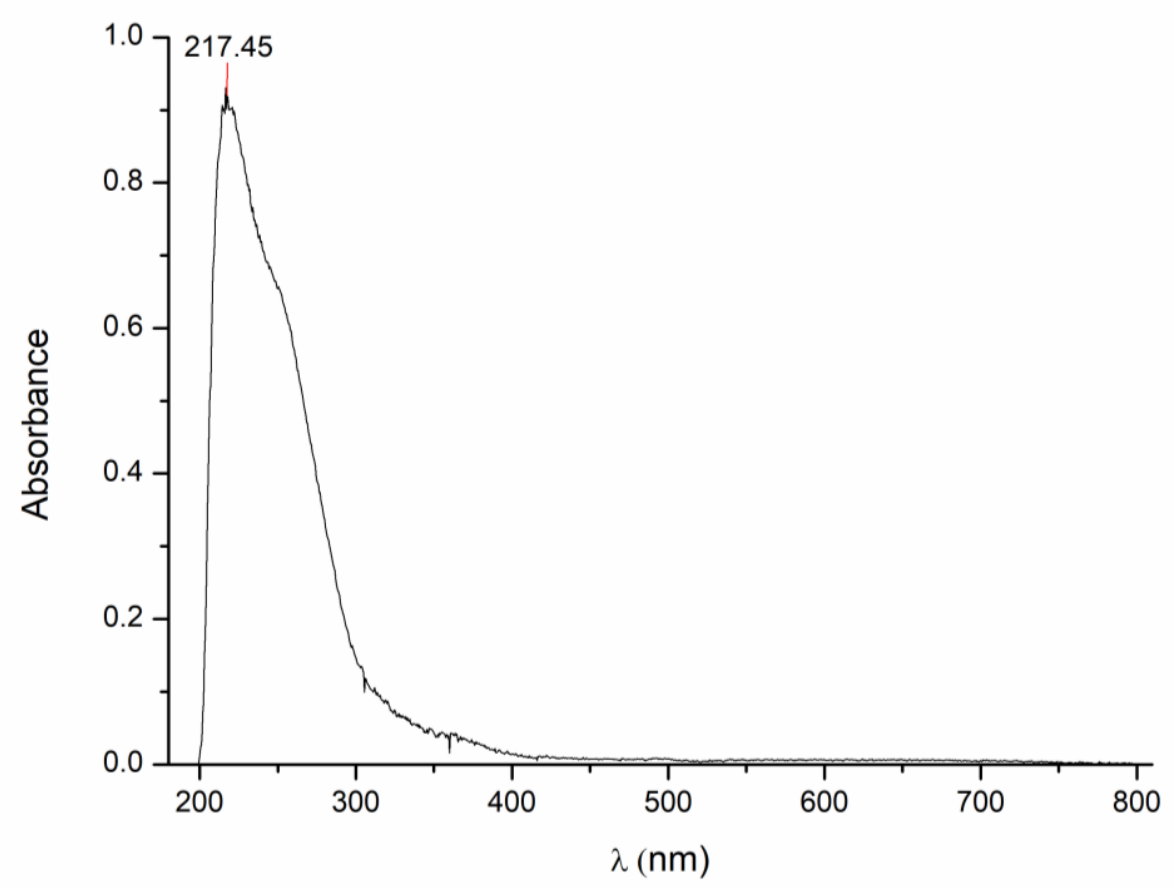

Figure S12. ${ }^{1} \mathrm{H} \mathrm{NMR}$ spectrum $\left(400 \mathrm{MHz}, \mathrm{CDCl}_{3}\right.$ ) of the compound 2

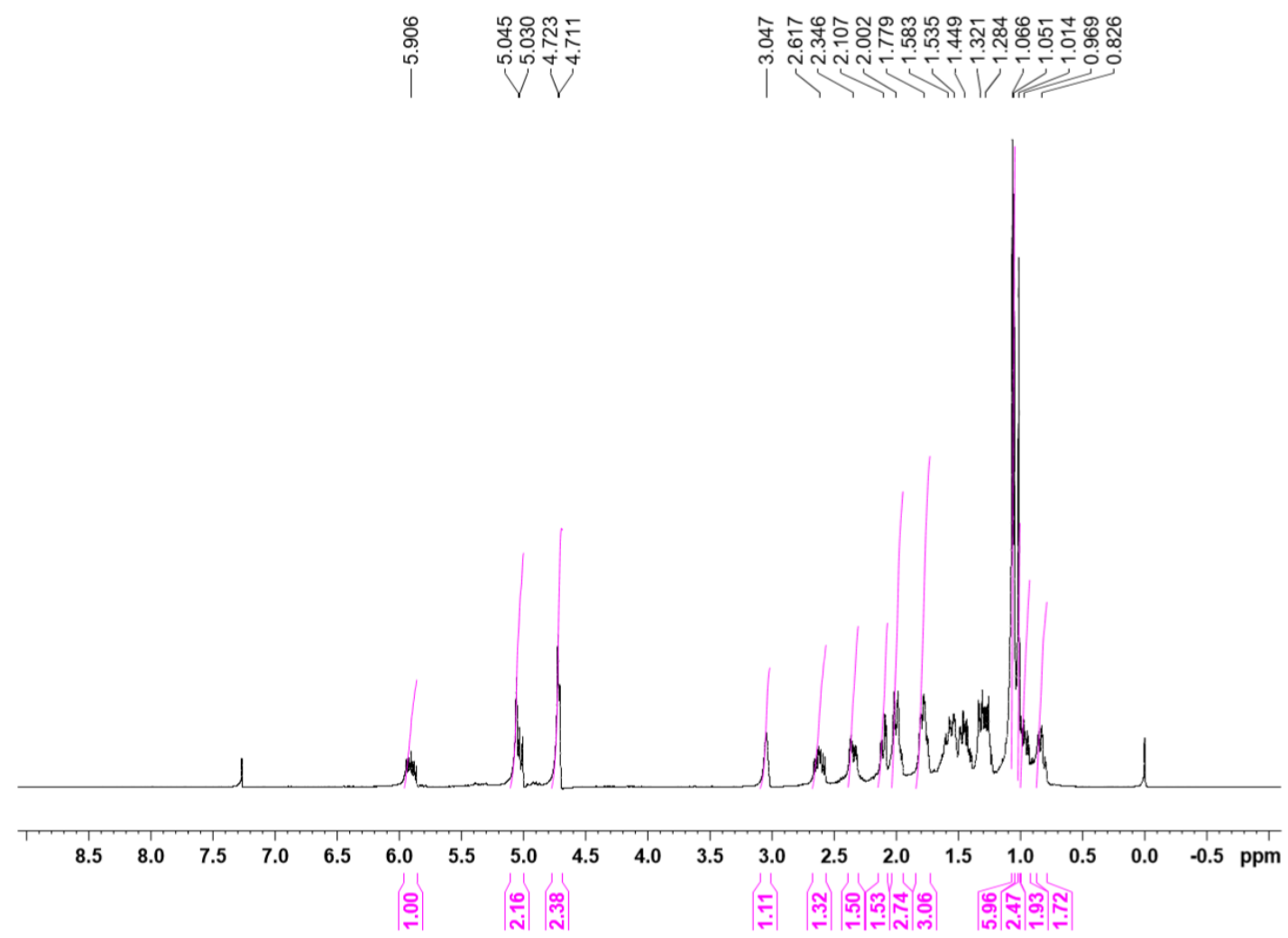


Figure S13. ${ }^{13} \mathrm{C}$ NMR spectrum $\left(150 \mathrm{MHz}, \mathrm{CDCl}_{3}\right)$ of the compound 2

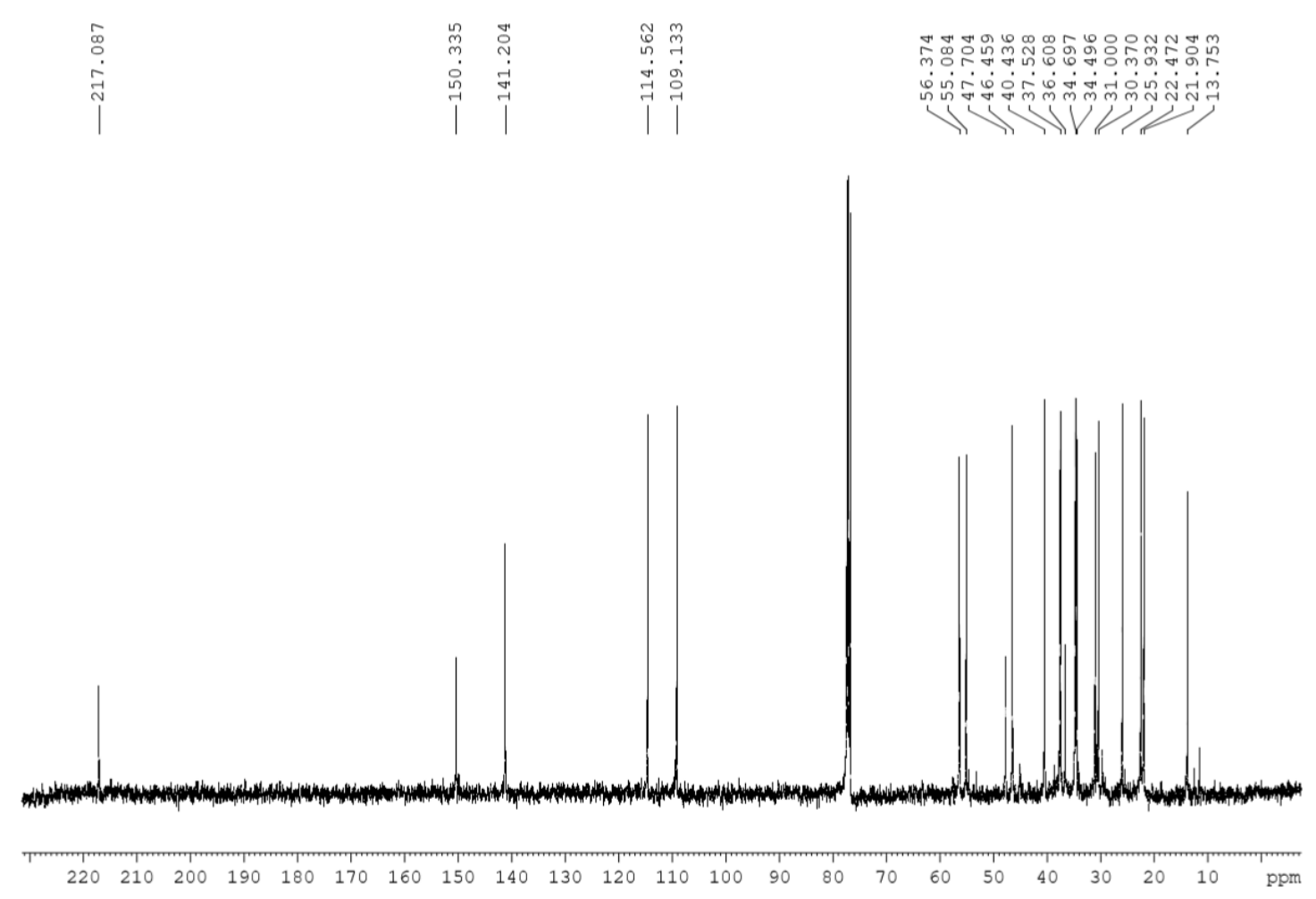

Figure S14. HSQC spectrum $\left(400 \mathrm{MHz}, \mathrm{CDCl}_{3}\right)$ of the new compound 2

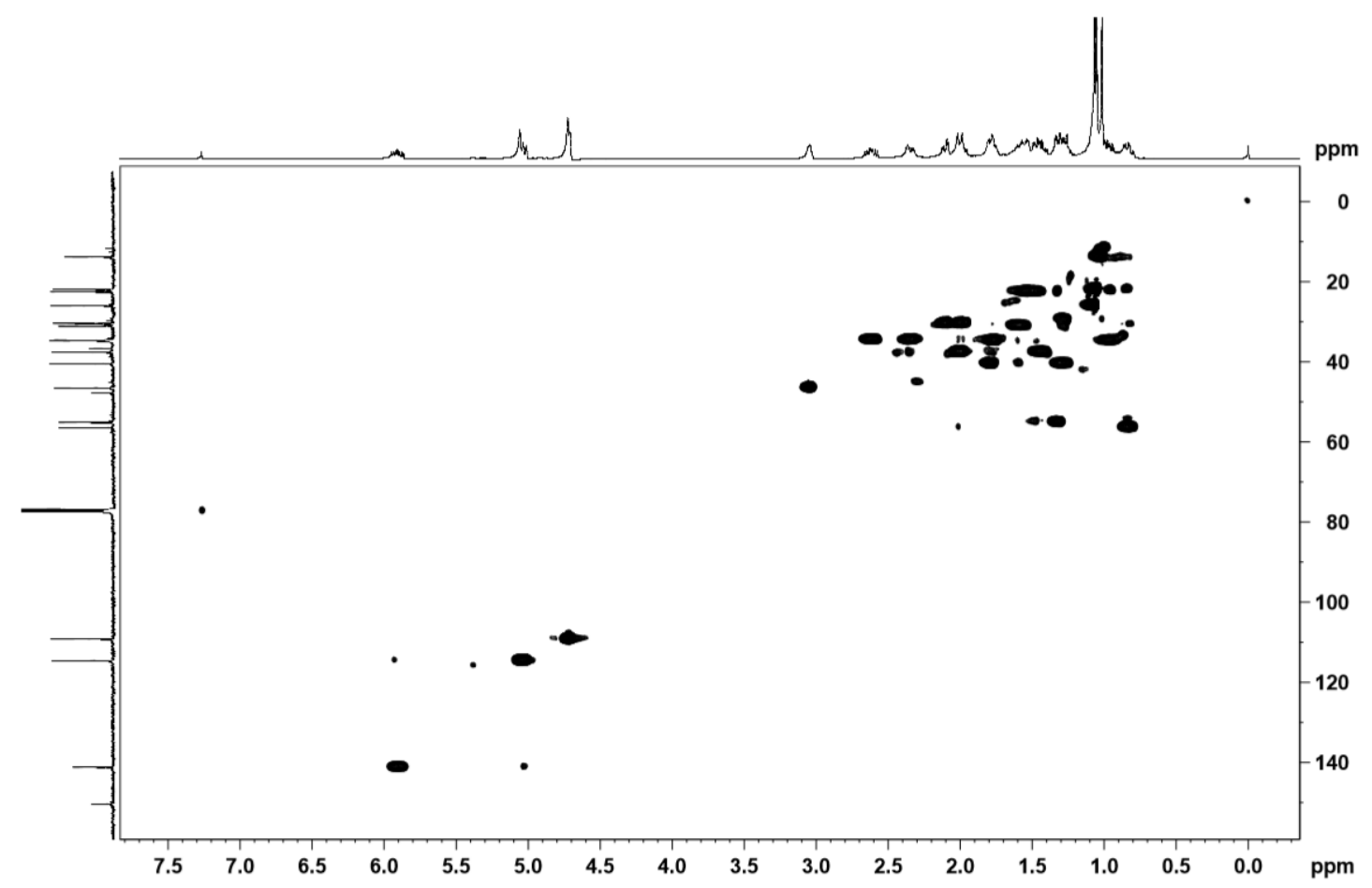


Figure S15. HMBC spectrum $\left(400 \mathrm{MHz}, \mathrm{CDCl}_{3}\right)$ of the compound 2

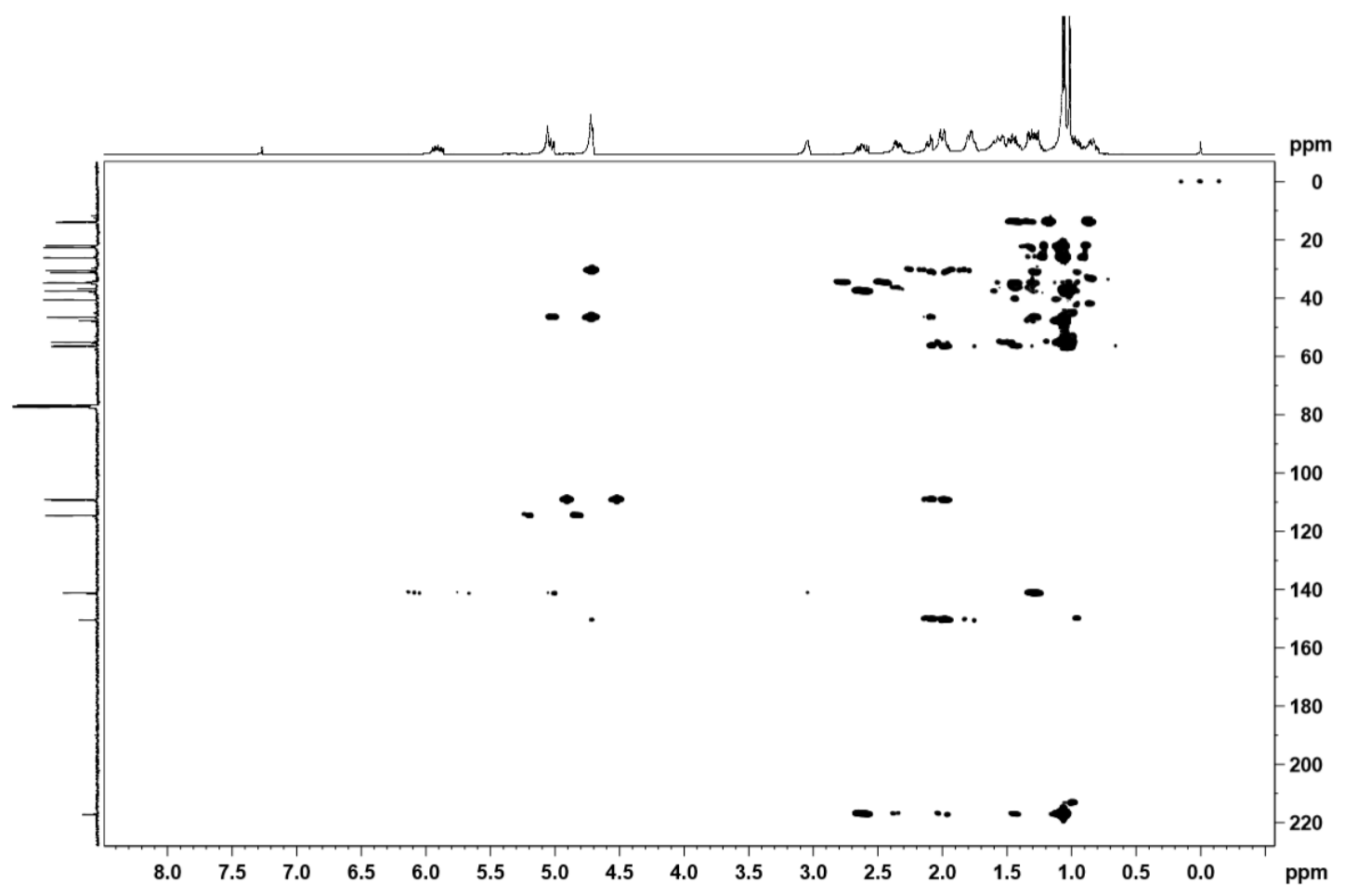

Figure S16. NOE Spectrum of the compound 2

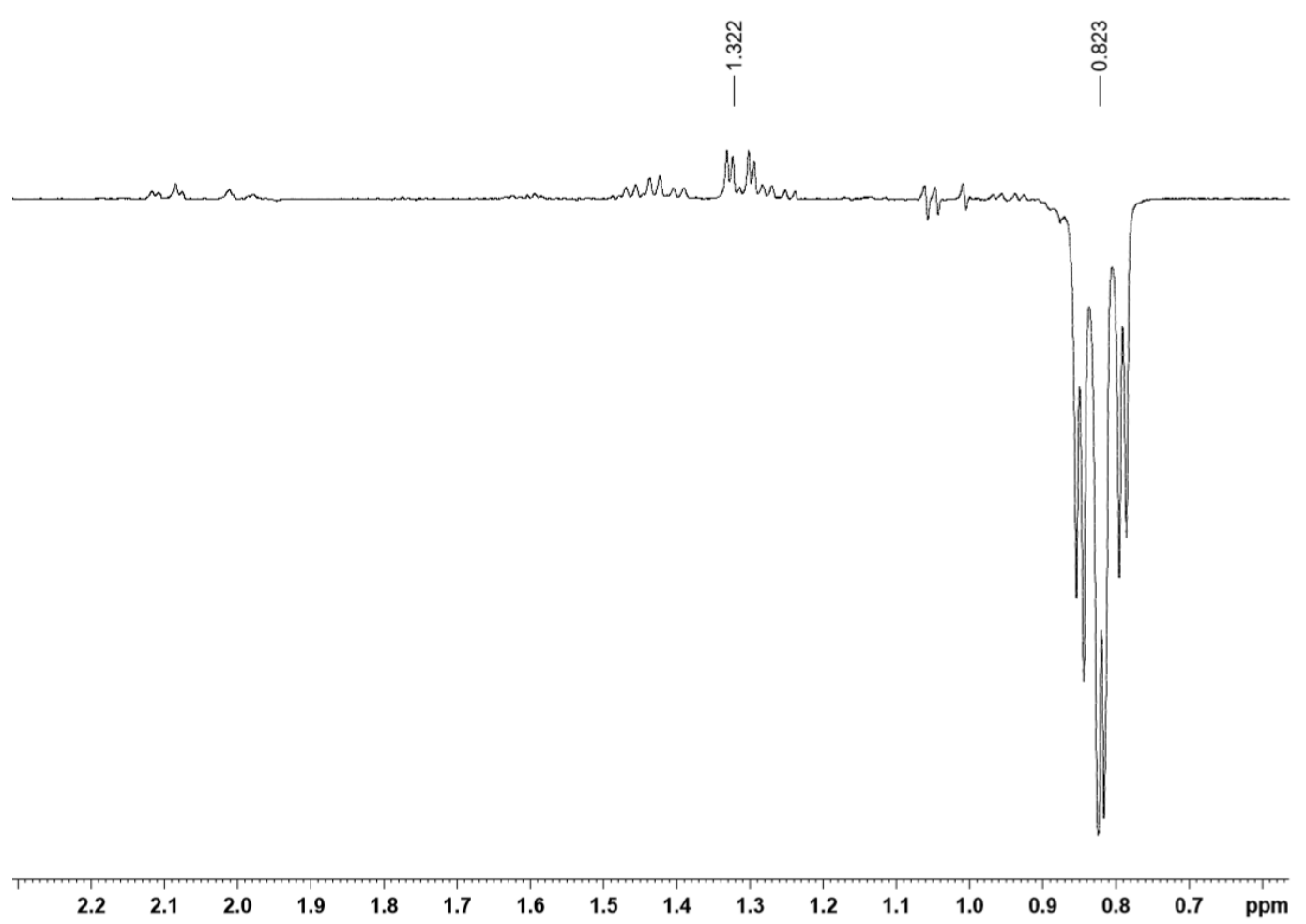


Figure S17. HRESIMS spectrum of the compound 3

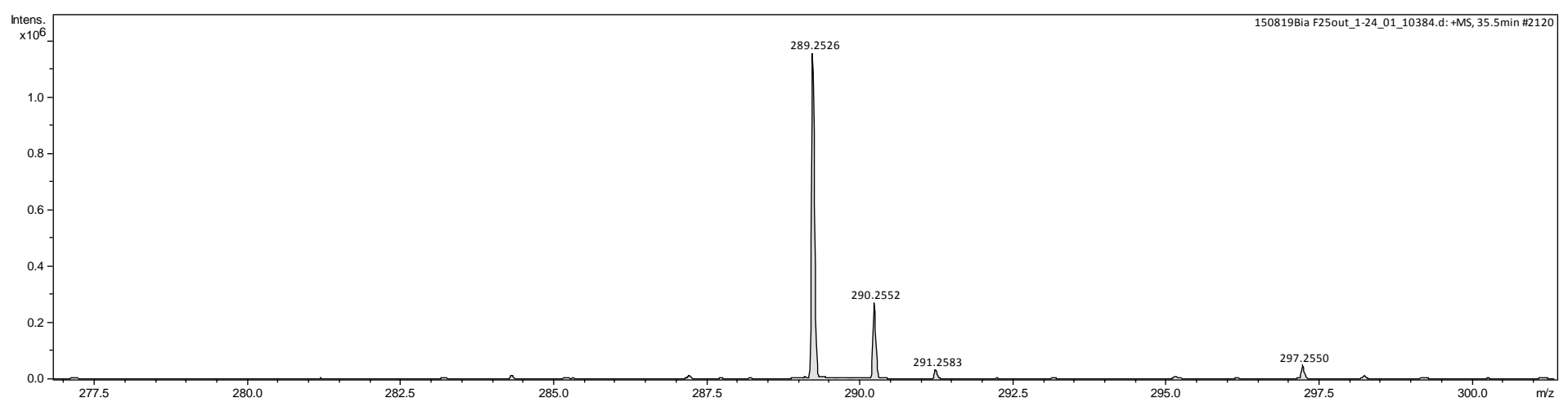

Figure S18. IR Spectrum of the compound 3

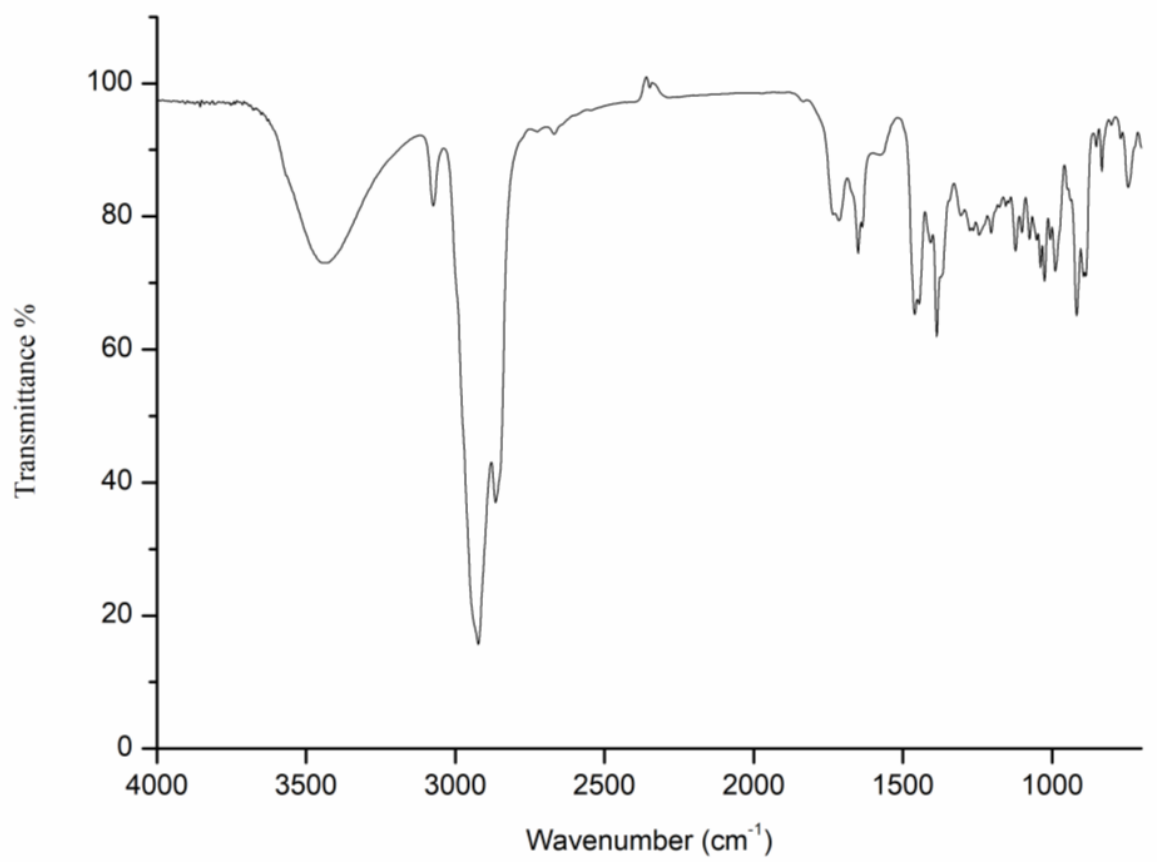


Figure S19. UV Spectrum of the compound 3

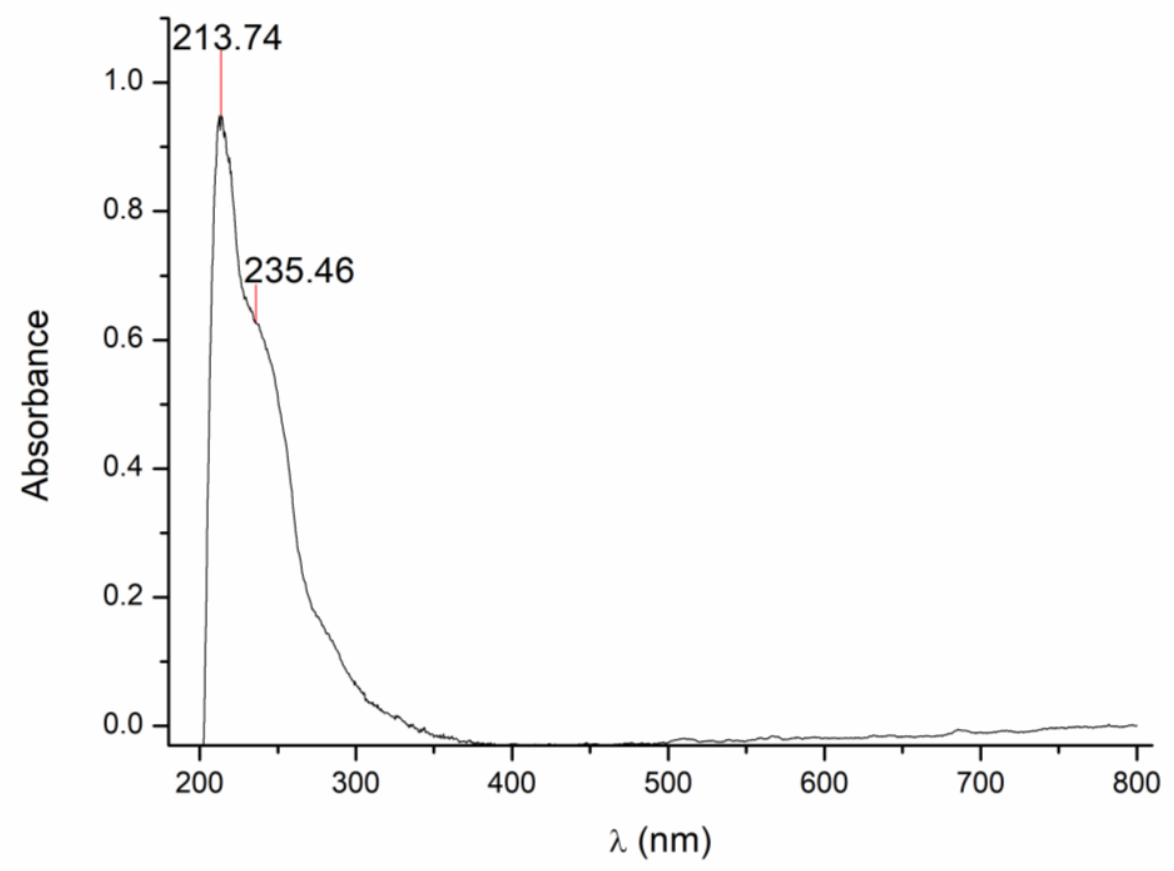

Figure S20. ${ }^{1} \mathrm{H}$ NMR spectrum $\left(400 \mathrm{MHz}, \mathrm{CDCl}_{3}\right)$ of the compound 3

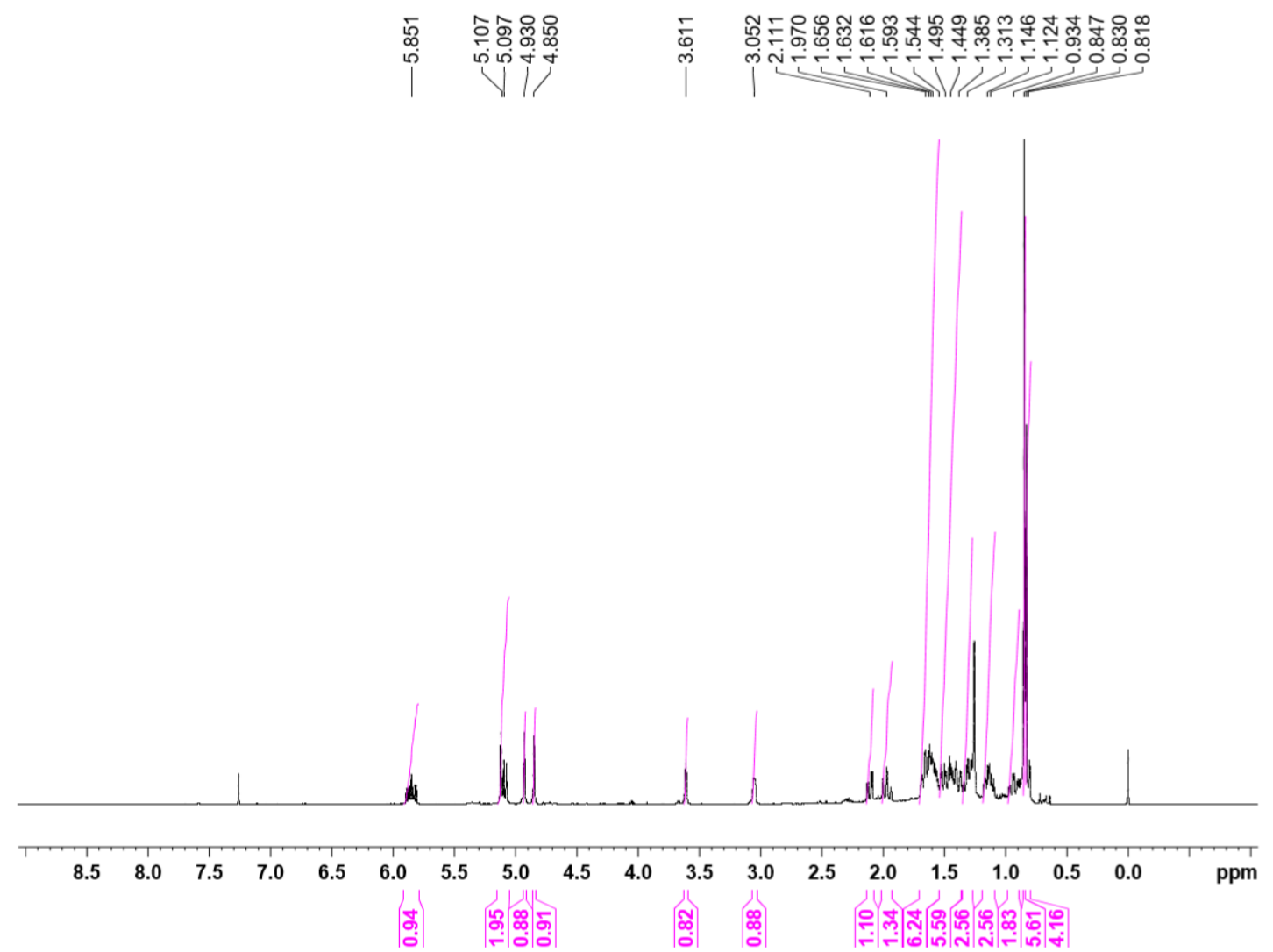


Figure S21. ${ }^{13} \mathrm{C}$ NMR spectrum $\left(150 \mathrm{MHz}, \mathrm{CDCl}_{3}\right)$ of the compound 3

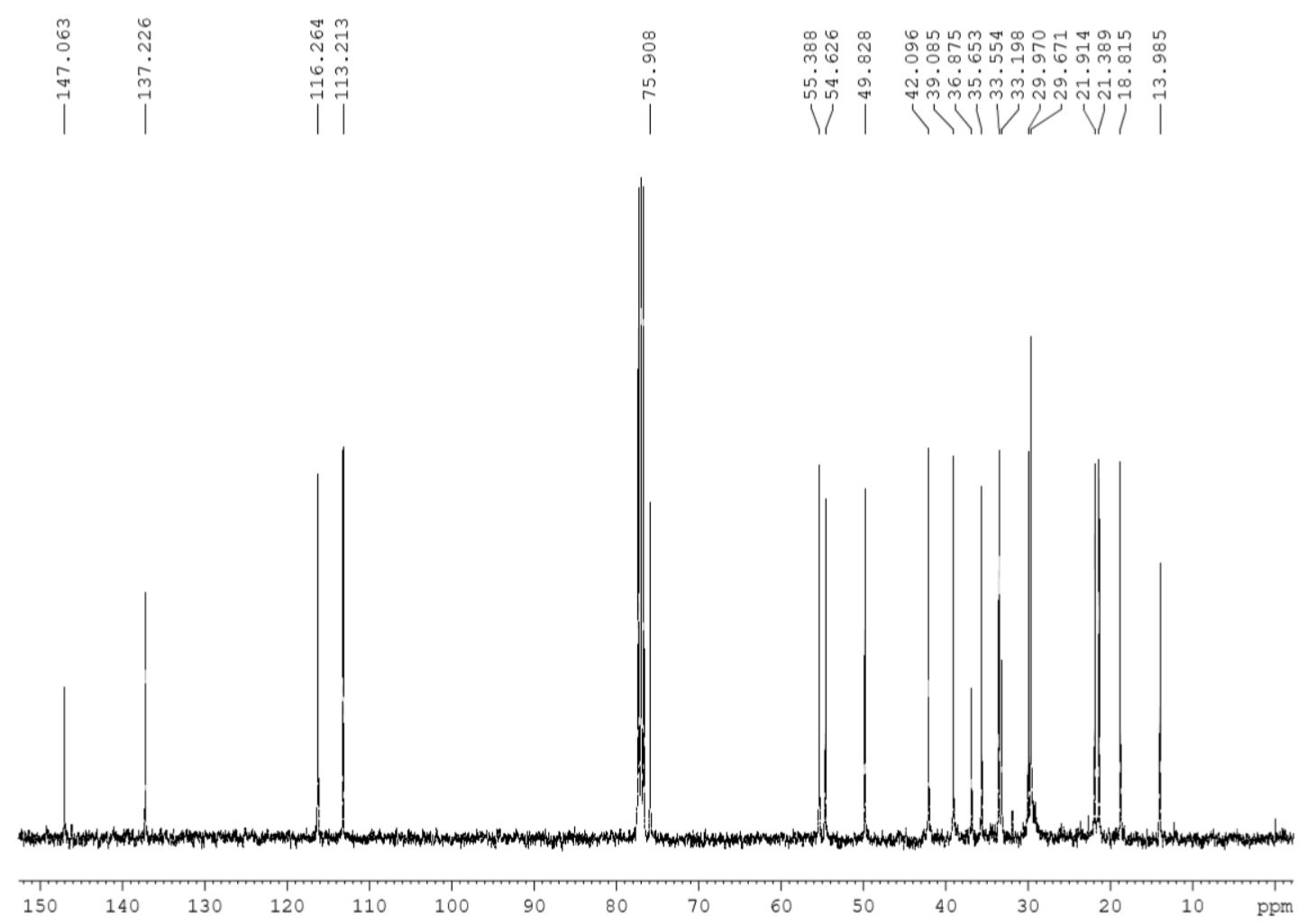

Figure S22. HSQC spectrum $\left(400 \mathrm{MHz}, \mathrm{CDCl}_{3}\right)$ of the new compound $\mathbf{3}$

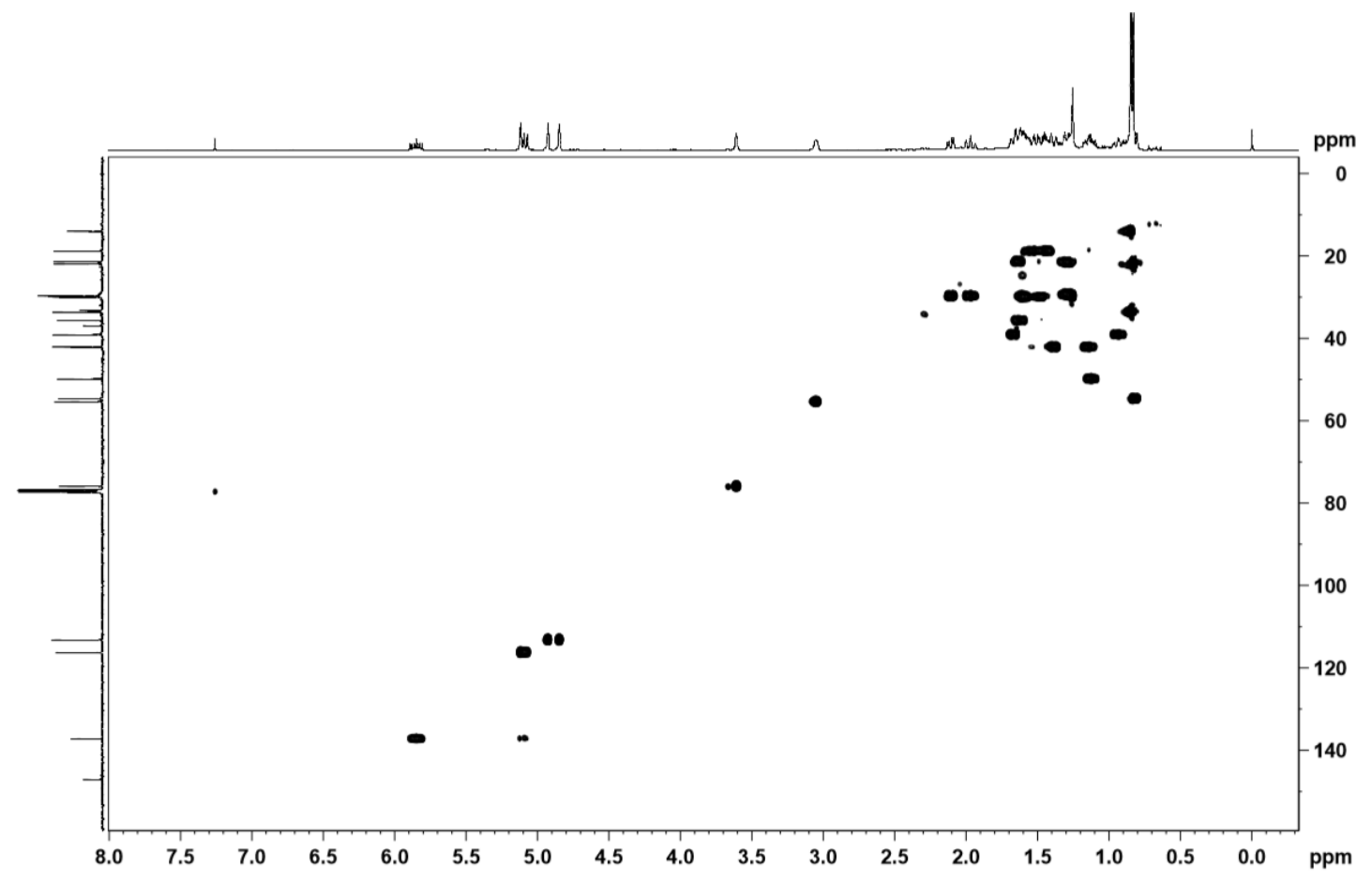


Figure S23. $\mathrm{HMBC}$ spectrum $\left(400 \mathrm{MHz}, \mathrm{CDCl}_{3}\right)$ of the compound 3

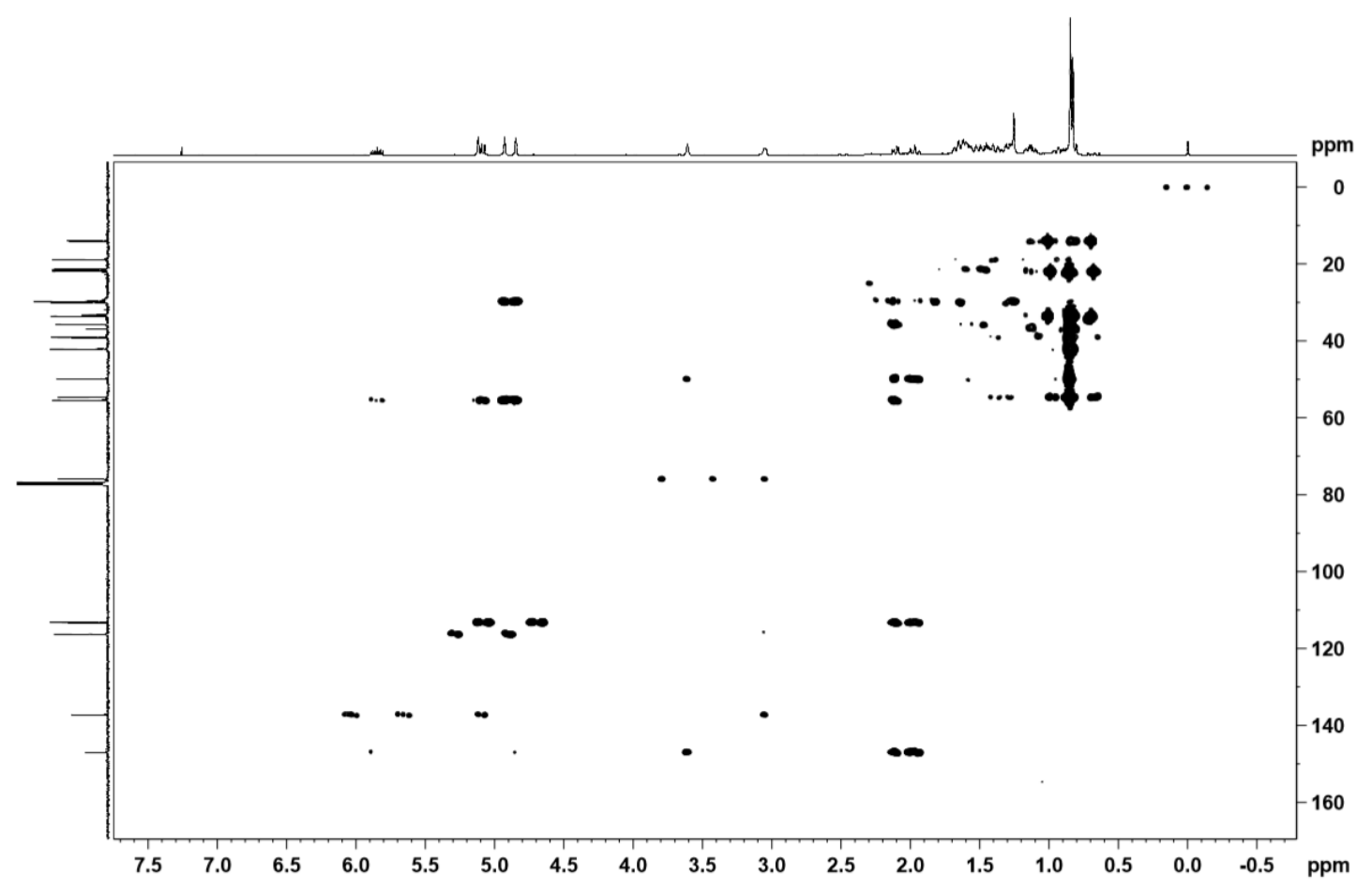

Figure S24. ${ }^{1} \mathrm{H}-{ }^{1} \mathrm{HCOSY}$ spectrum $\left(400 \mathrm{MHz}, \mathrm{CDCl}_{3}\right)$ of the compound $\mathbf{3}$

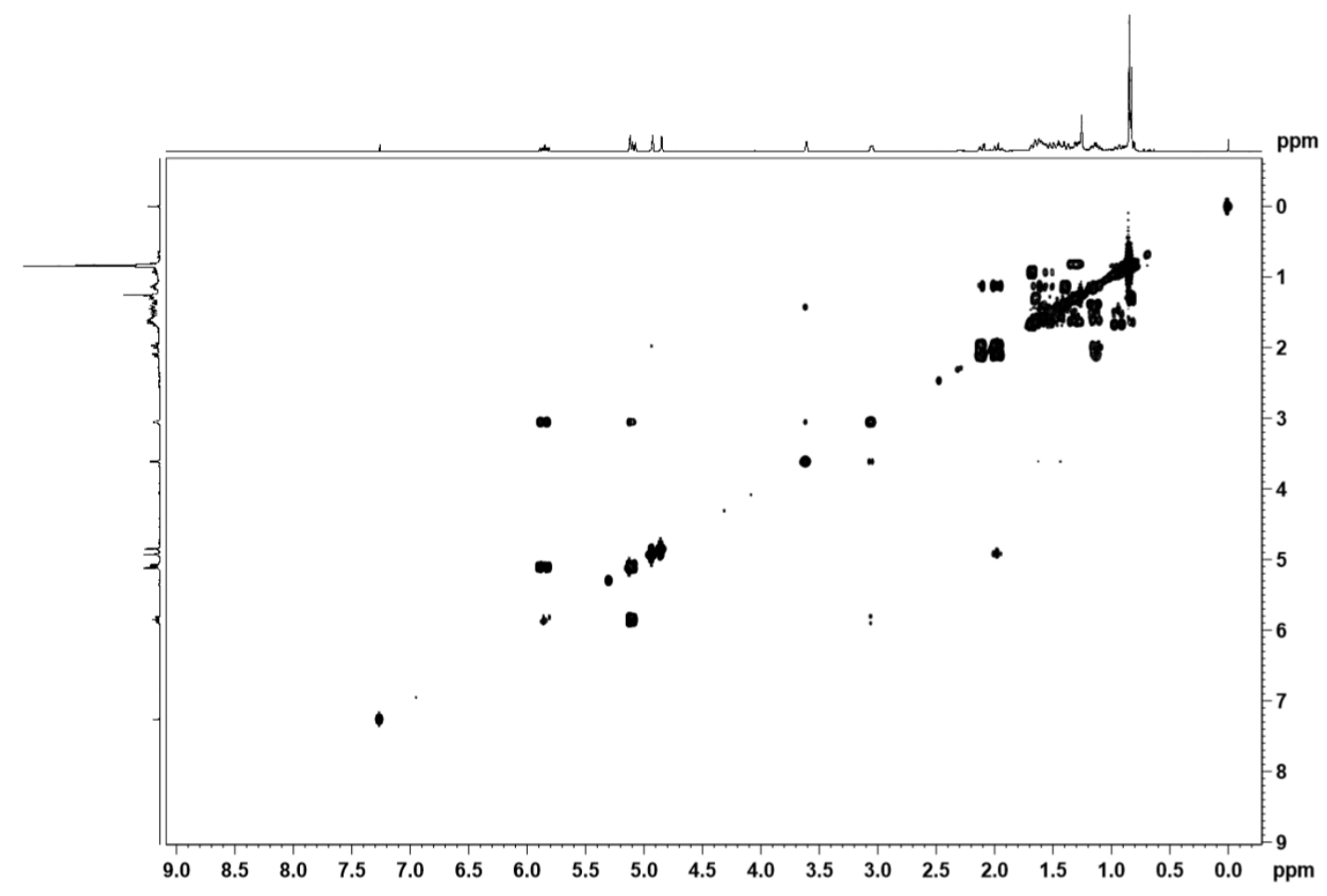


Figure S25. NOE Spectrum of the compound 3

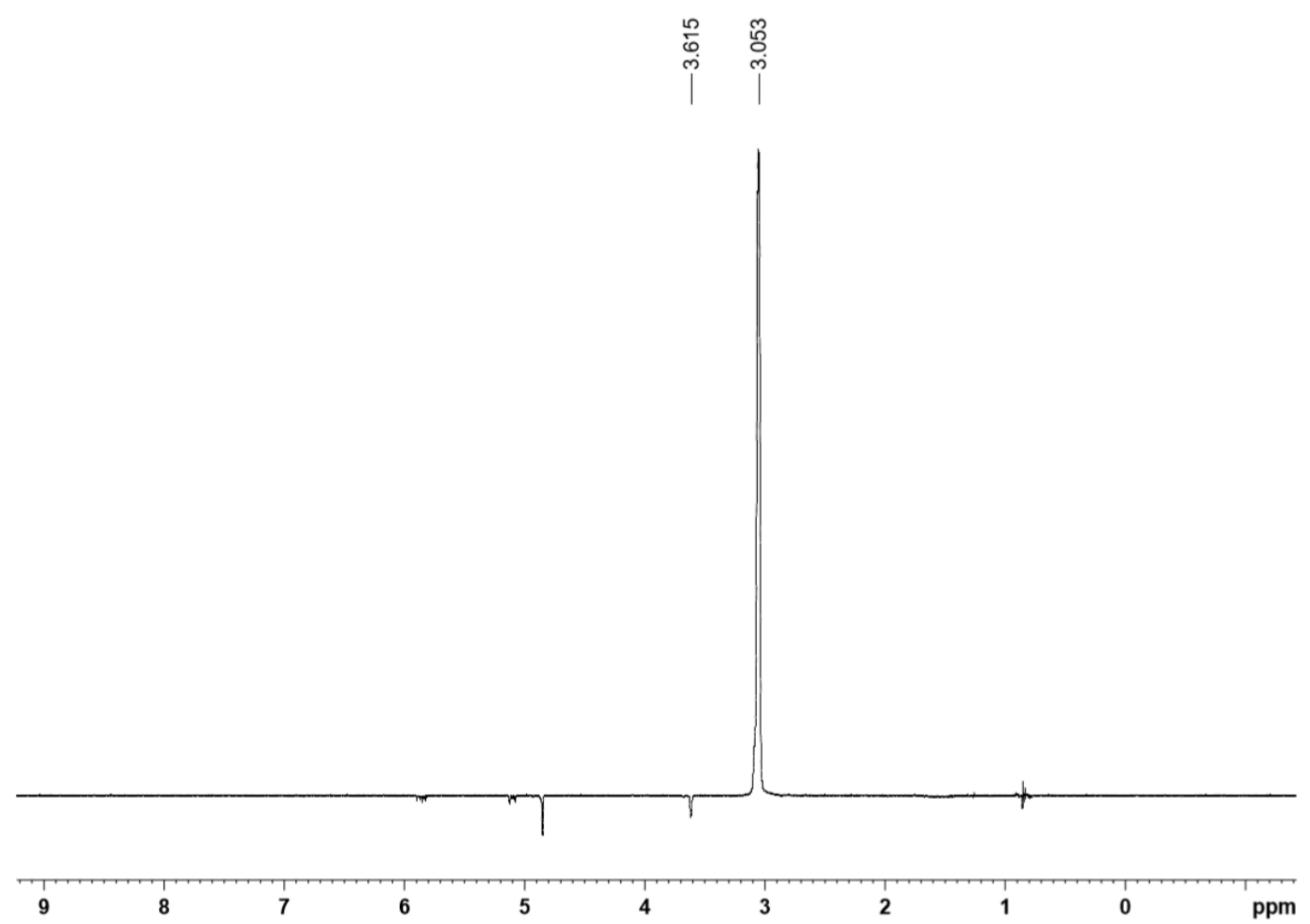

Figure S26. HRESIMS spectrum of the compound 4

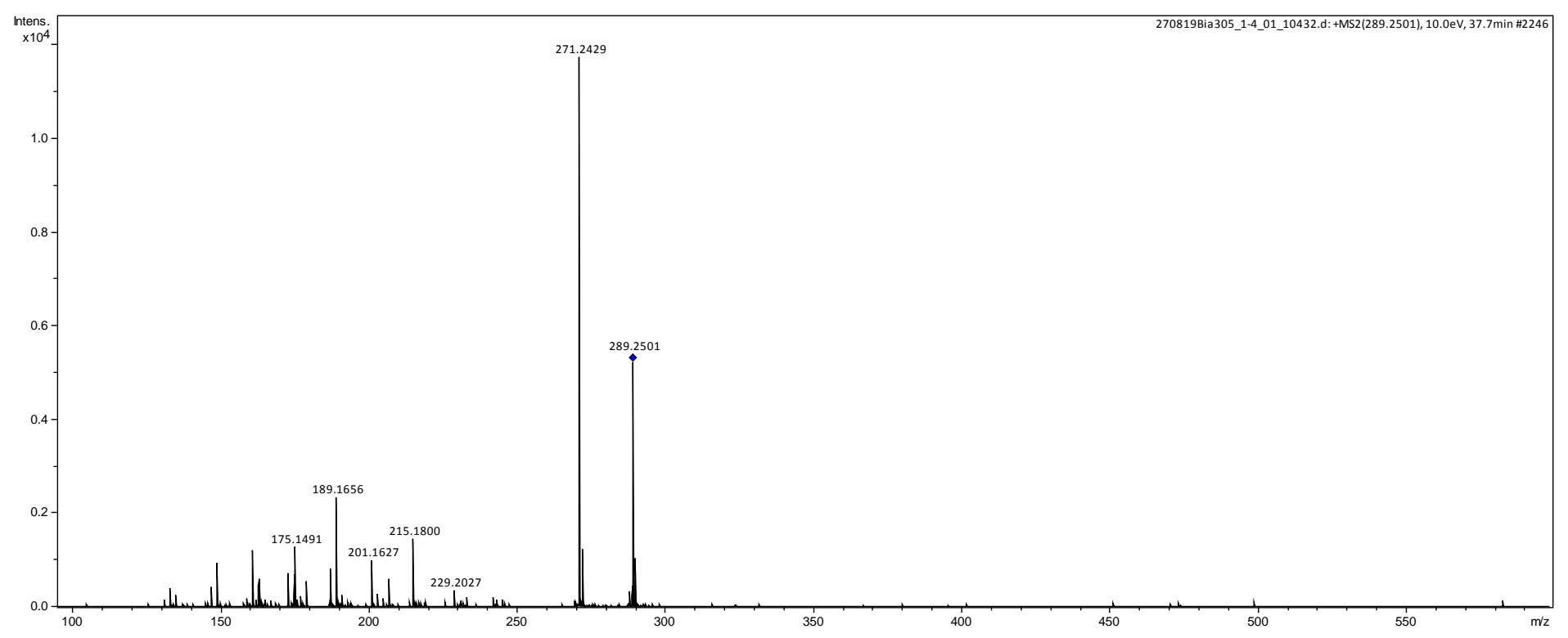


Figure S27. IR Spectrum of the compound 4

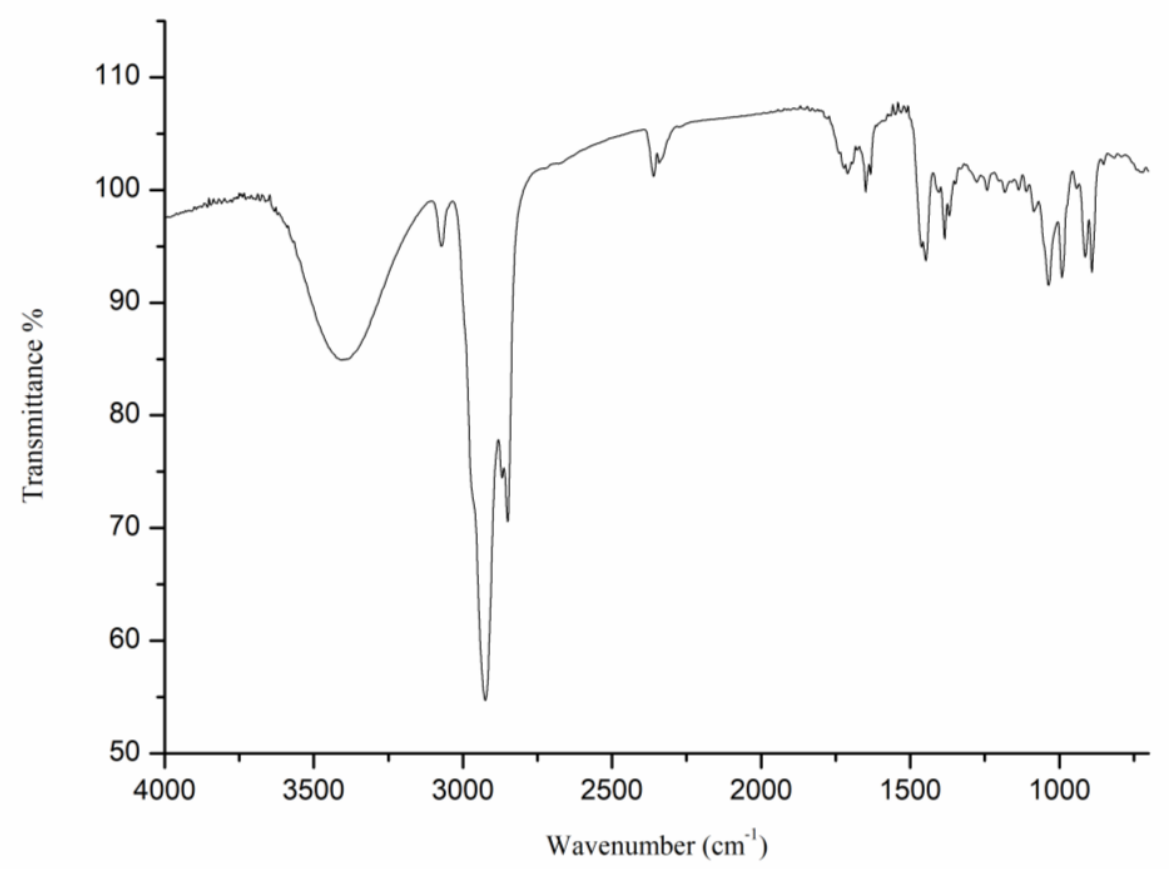

Figure S28. UV Spectrum of the compound 4

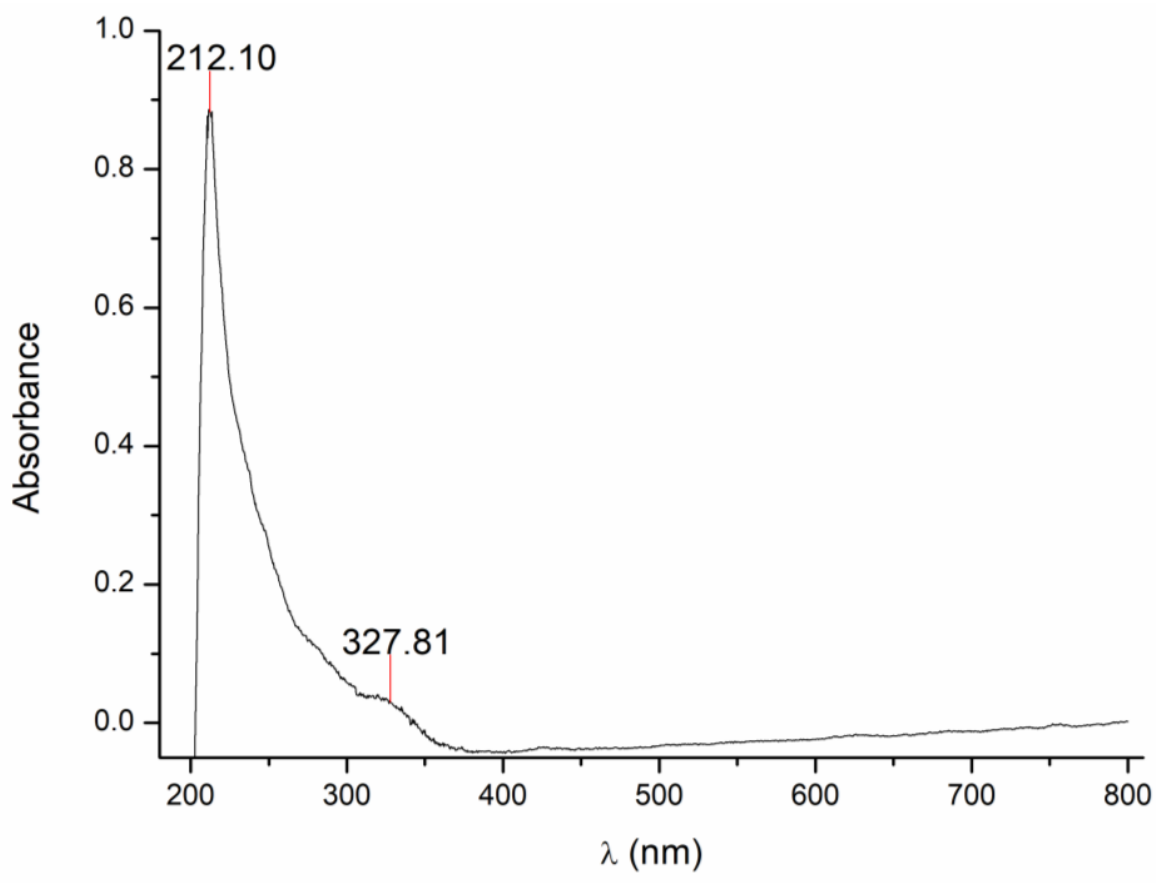


Figure S29. ${ }^{1} \mathrm{H}$ NMR spectrum $\left(400 \mathrm{MHz}, \mathrm{CDCl}_{3}\right)$ of the compound 4

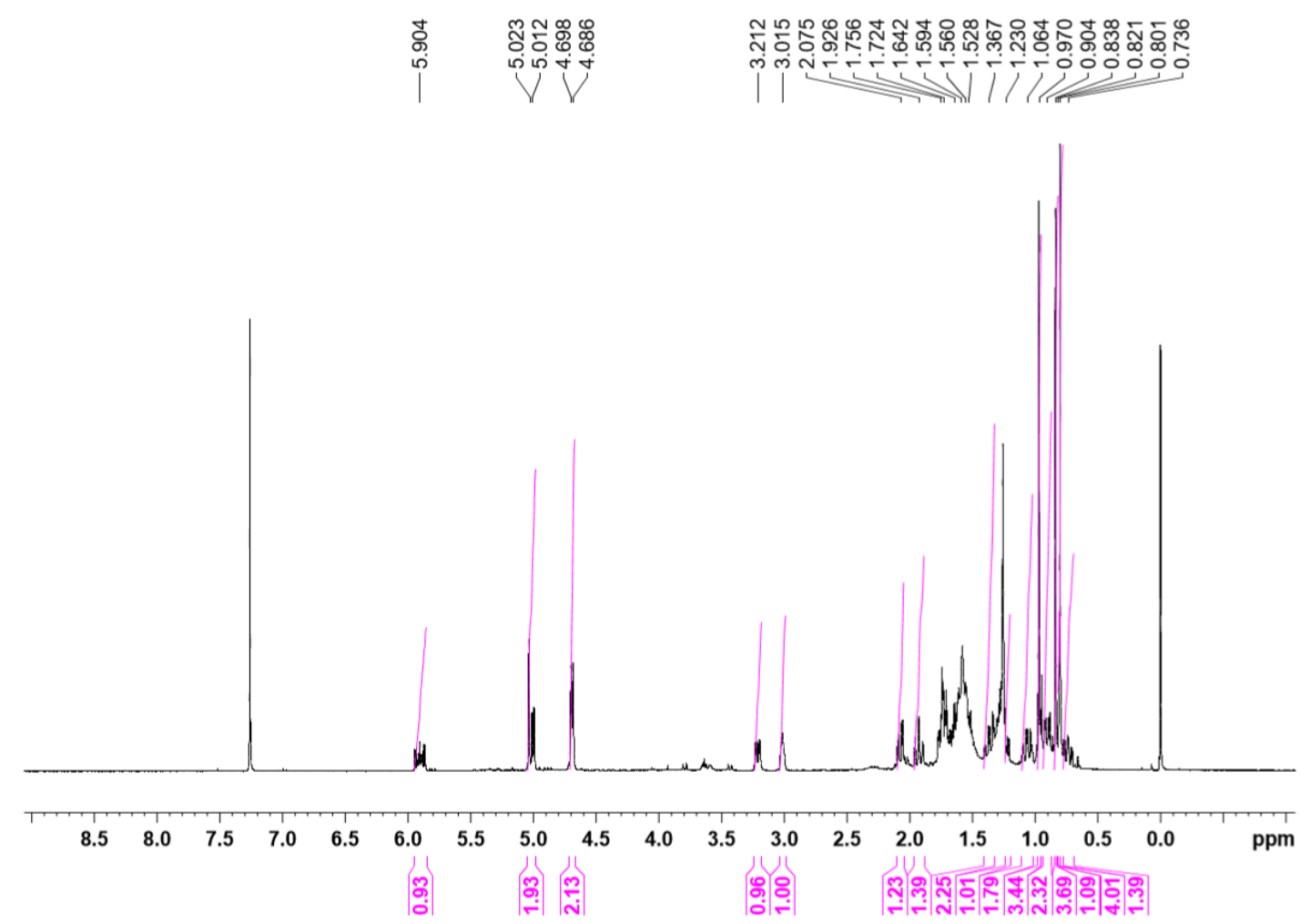

Figure S30. ${ }^{13} \mathrm{C}$ NMR spectrum $\left(150 \mathrm{MHz}, \mathrm{CDCl}_{3}\right)$ of the compound 4
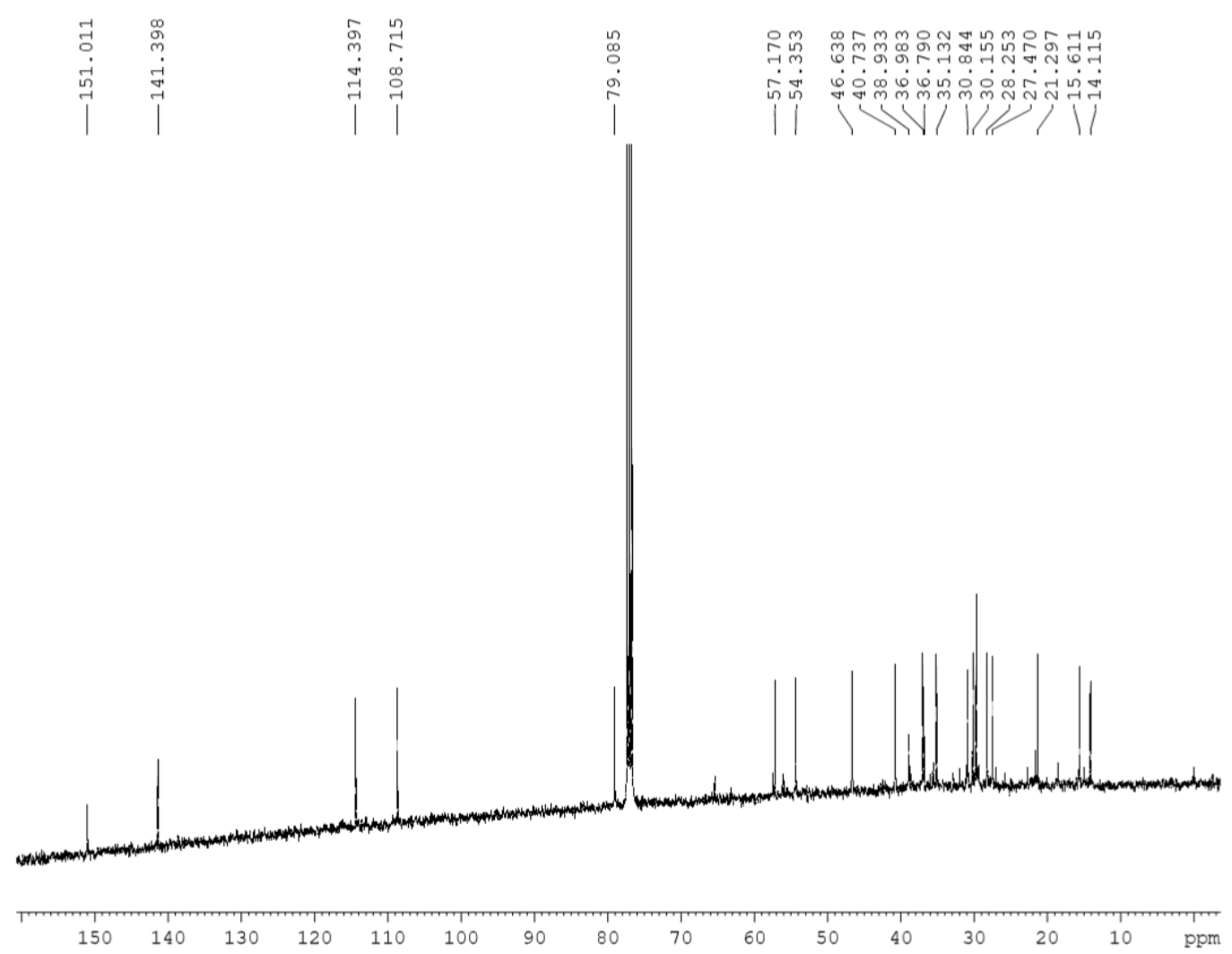
Figure S31. HSQC spectrum $\left(400 \mathrm{MHz}, \mathrm{CDCl}_{3}\right)$ of the new compound 4

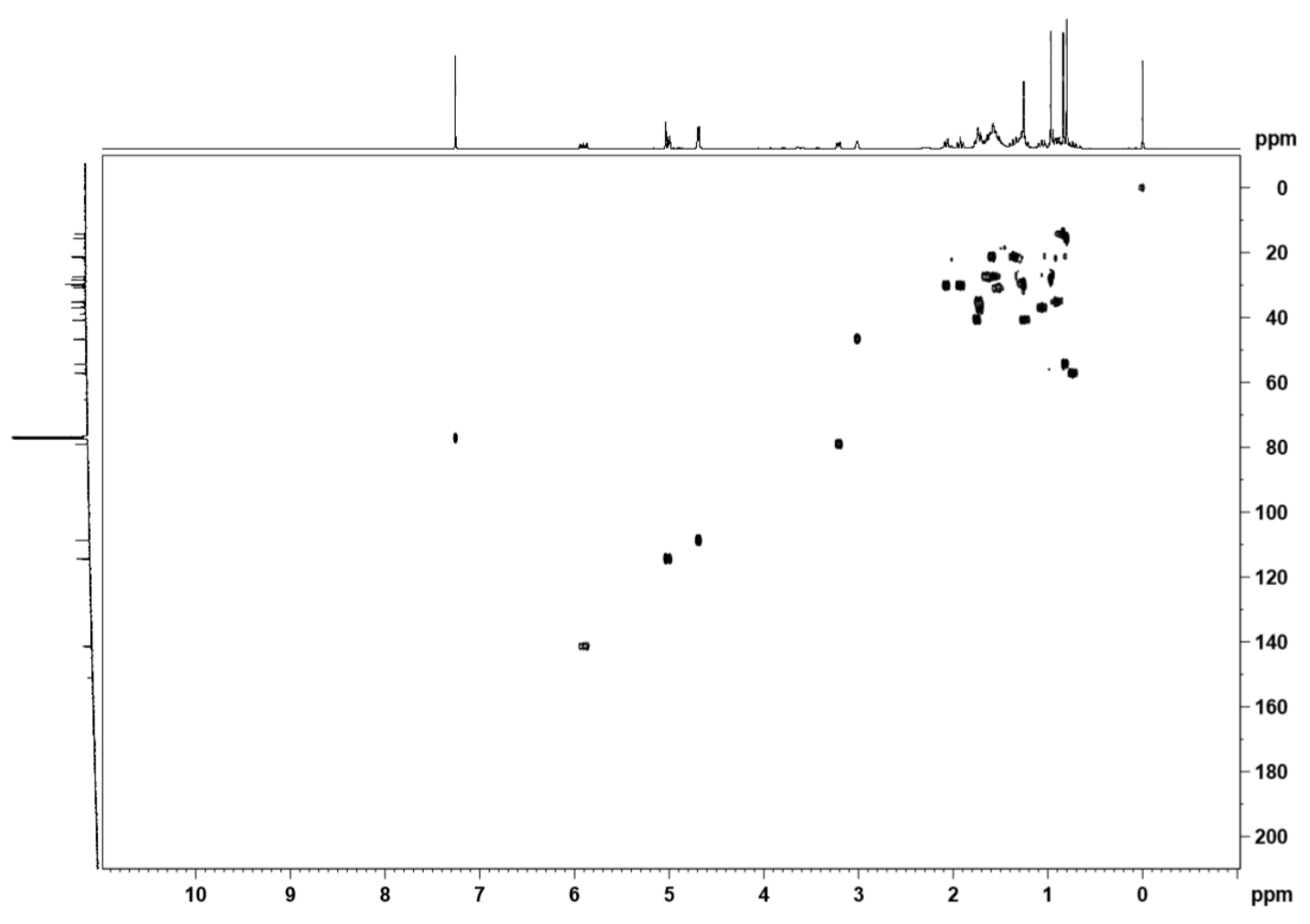

Figure S32. $\mathrm{HMBC}$ spectrum $\left(400 \mathrm{MHz}, \mathrm{CDCl}_{3}\right)$ of the compound 4

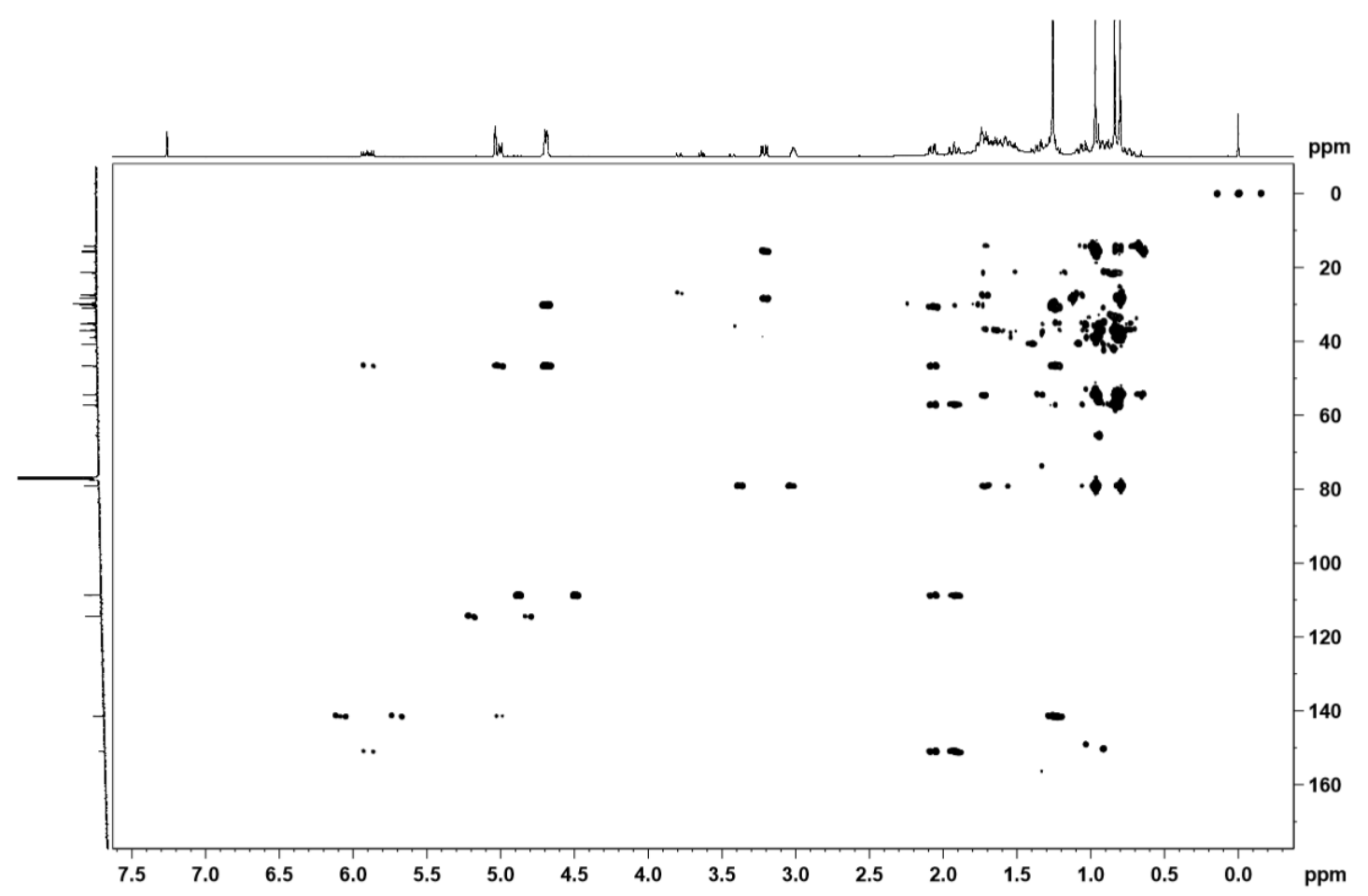


Figure S33. ${ }^{1} \mathrm{H}-{ }^{1} \mathrm{HCOSY}$ spectrum $\left(400 \mathrm{MHz}, \mathrm{CDCl}_{3}\right)$ of the compound 4

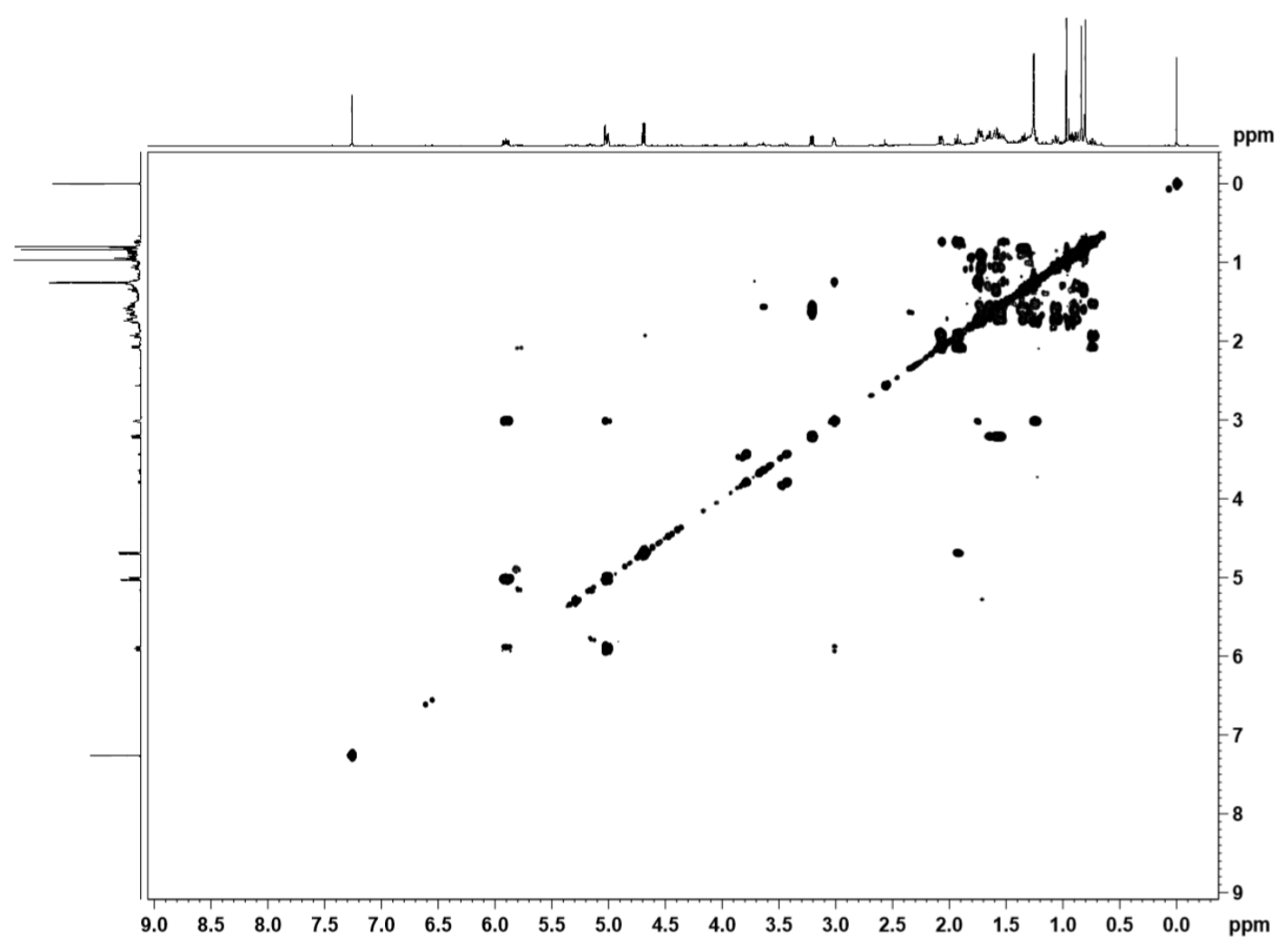

Figure S34. NOE Spectrum of the compound 4.

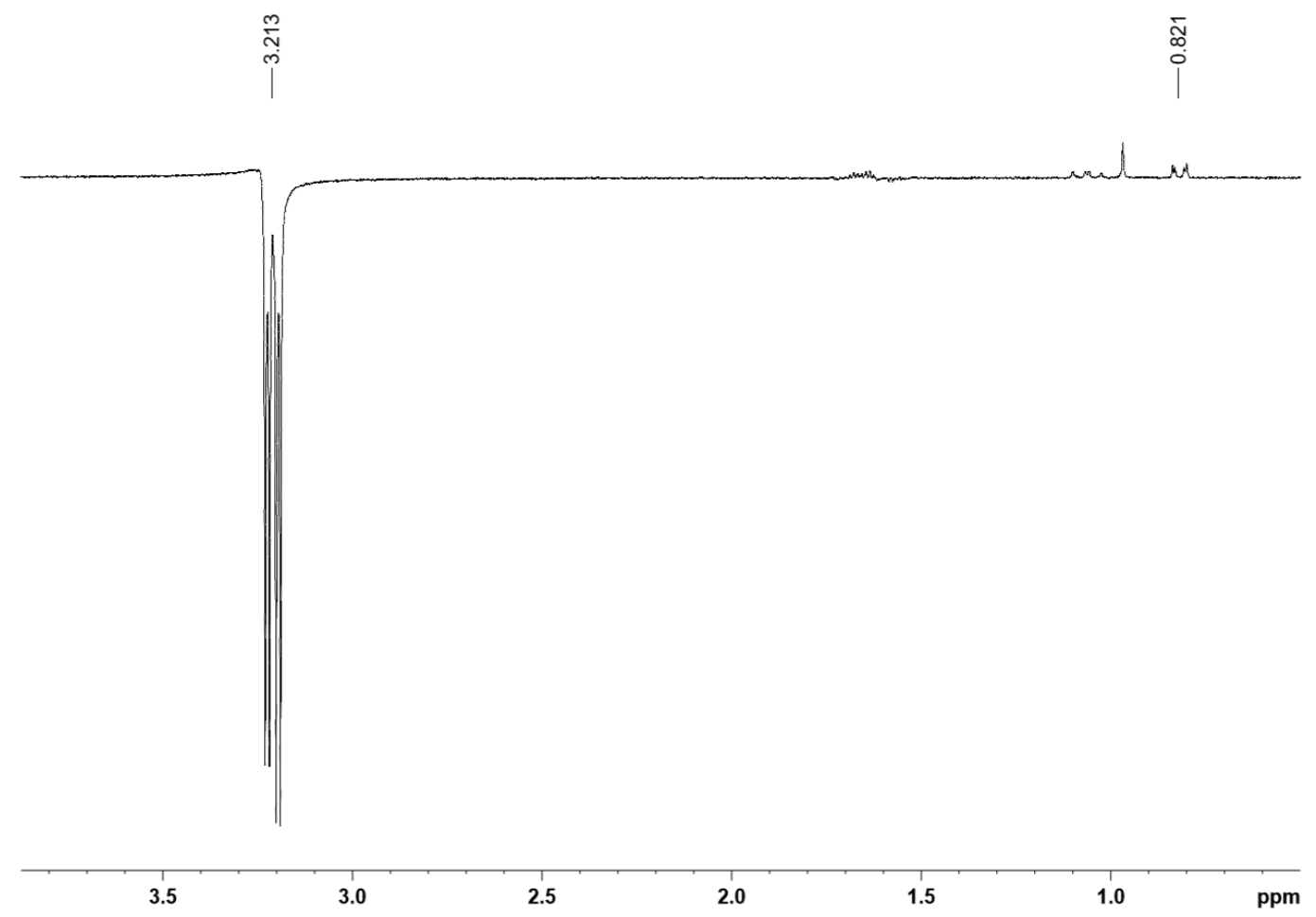


Figure S35. HRESIMS spectrum of the compound $\mathbf{5}$

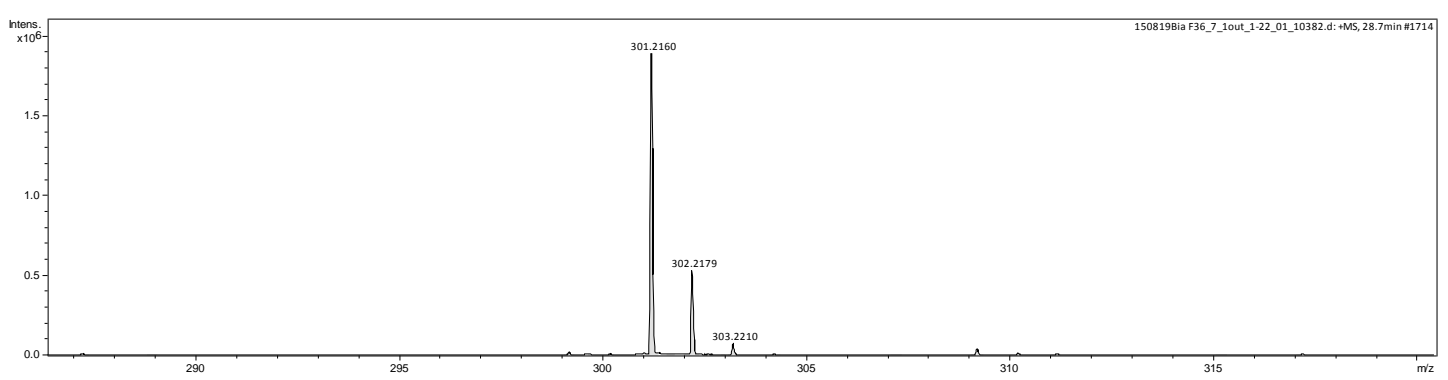

Figure S36. IR Spectrum of the compound 5

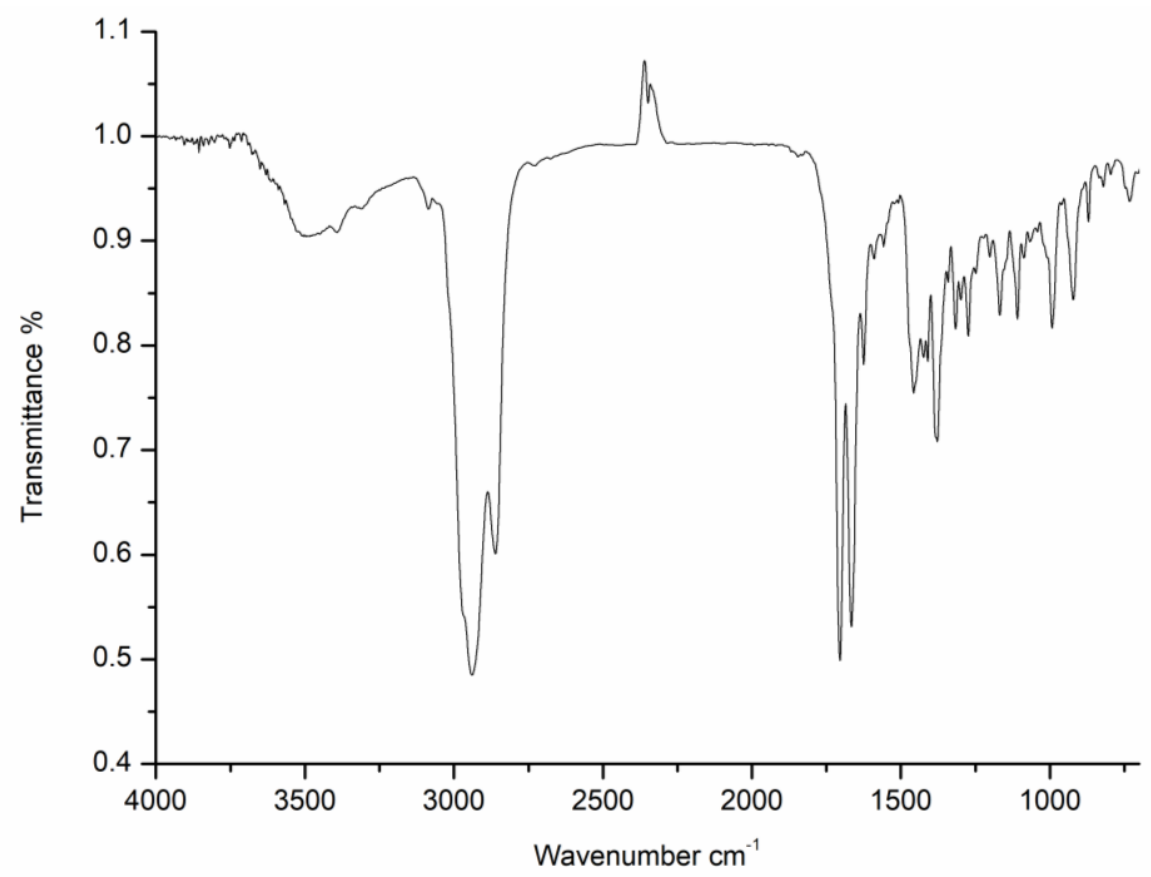


Figure S37. UV Spectrum of 5

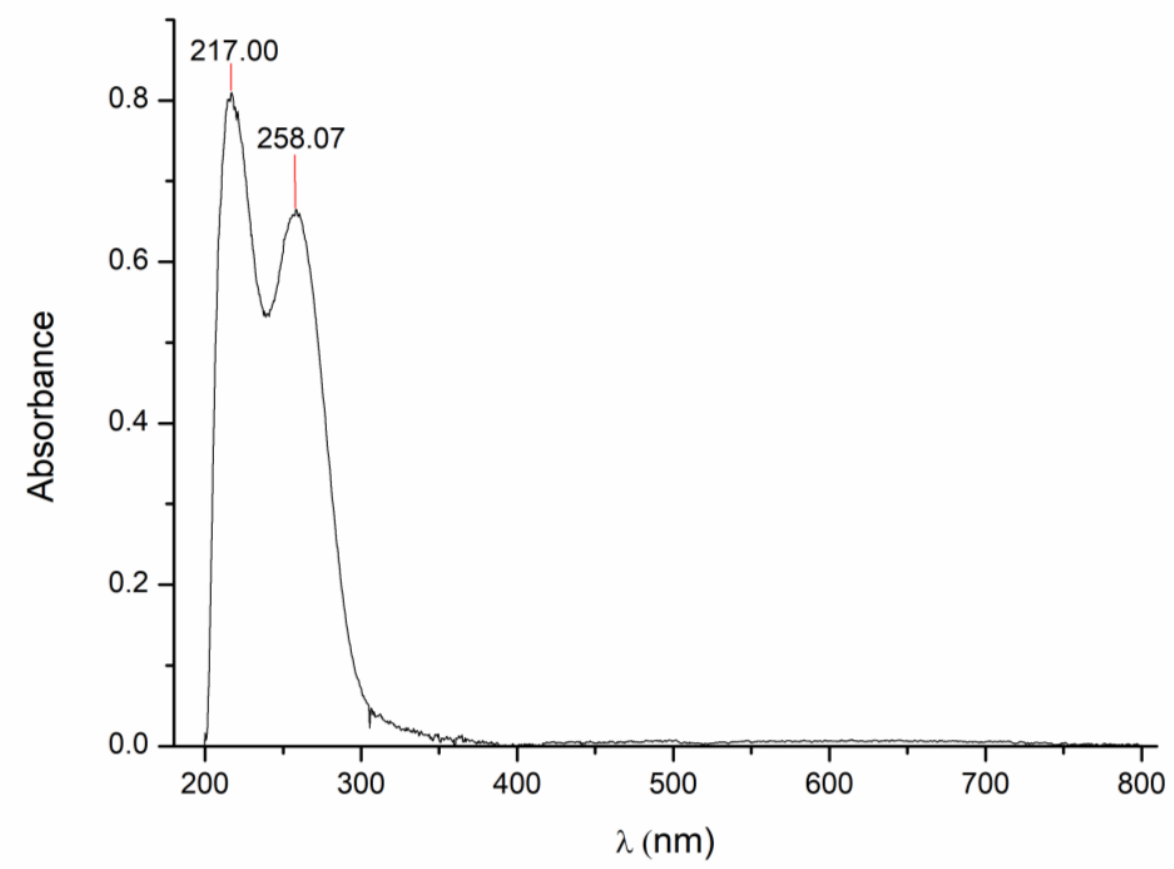

Figure S38. ${ }^{1} \mathrm{H} \mathrm{NMR}$ spectrum $\left(400 \mathrm{MHz}, \mathrm{CDCl}_{3}\right)$ of the compound $\mathbf{5}$

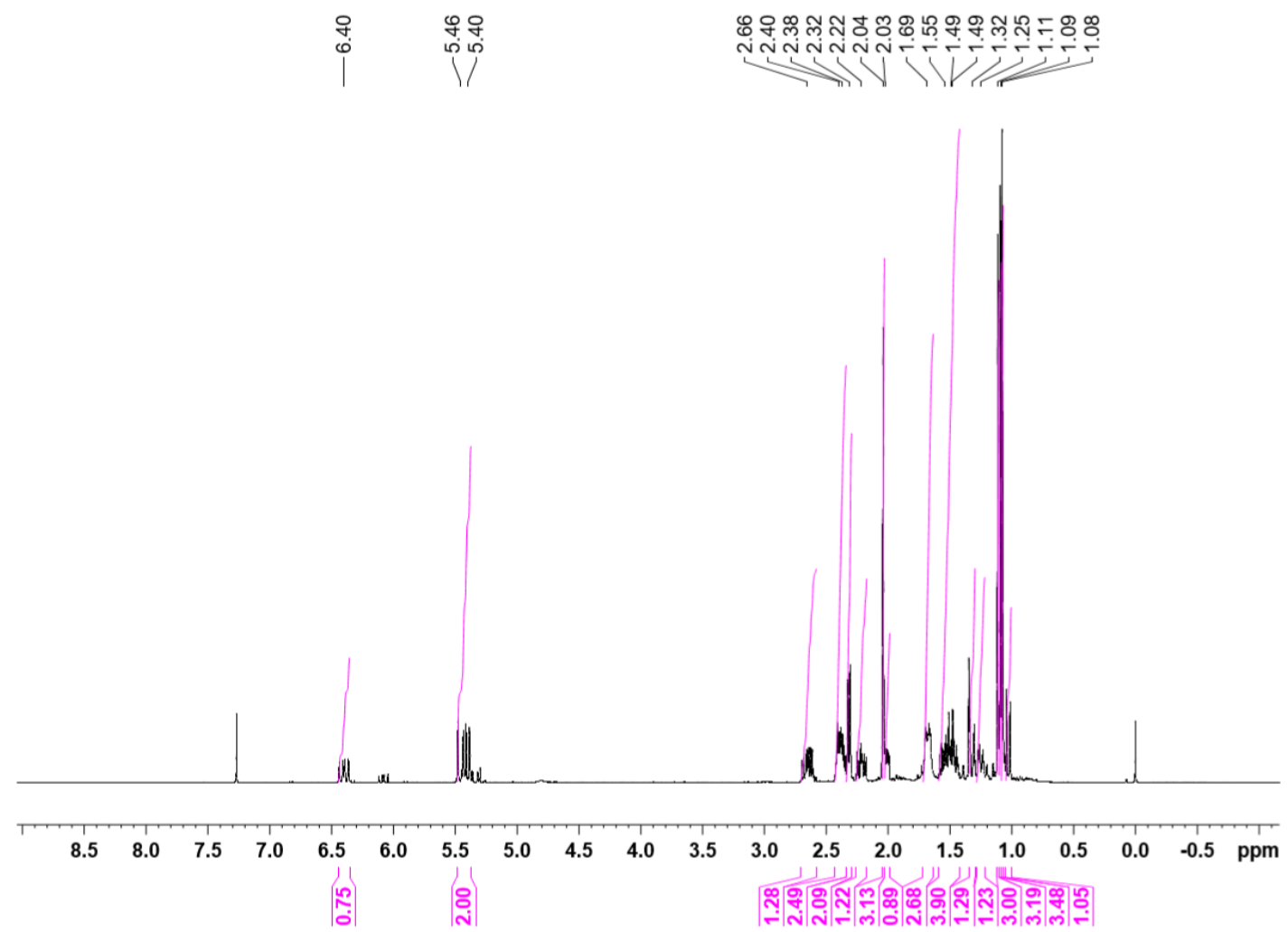


Figure S39. ${ }^{13} \mathrm{C}$ NMR spectrum $\left(150 \mathrm{MHz}, \mathrm{CDCl}_{3}\right)$ of the compound $\mathbf{5}$

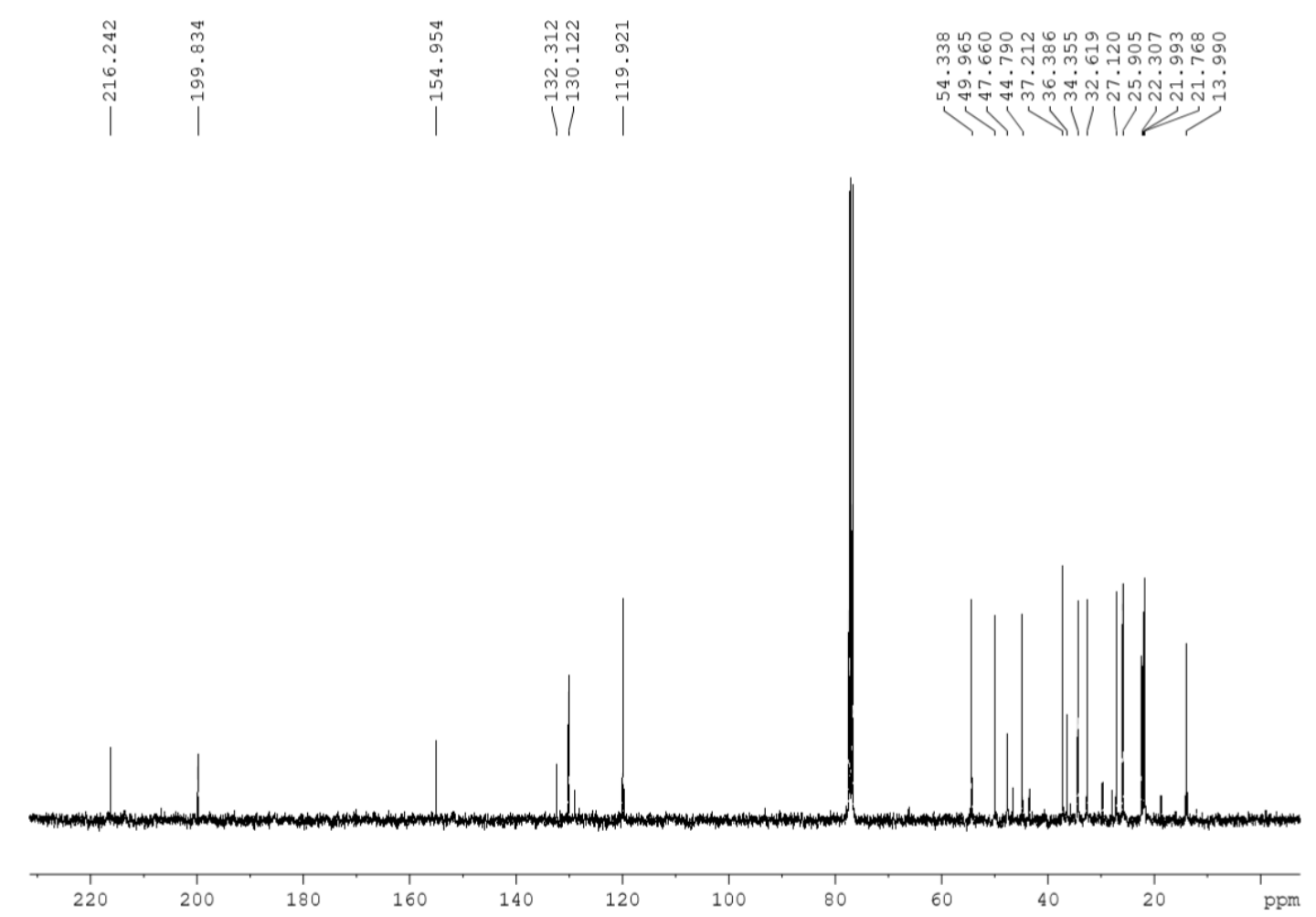

Figure S40. HSQC spectrum $\left(400 \mathrm{MHz}, \mathrm{CDCl}_{3}\right)$ of the new compound $\mathbf{5}$

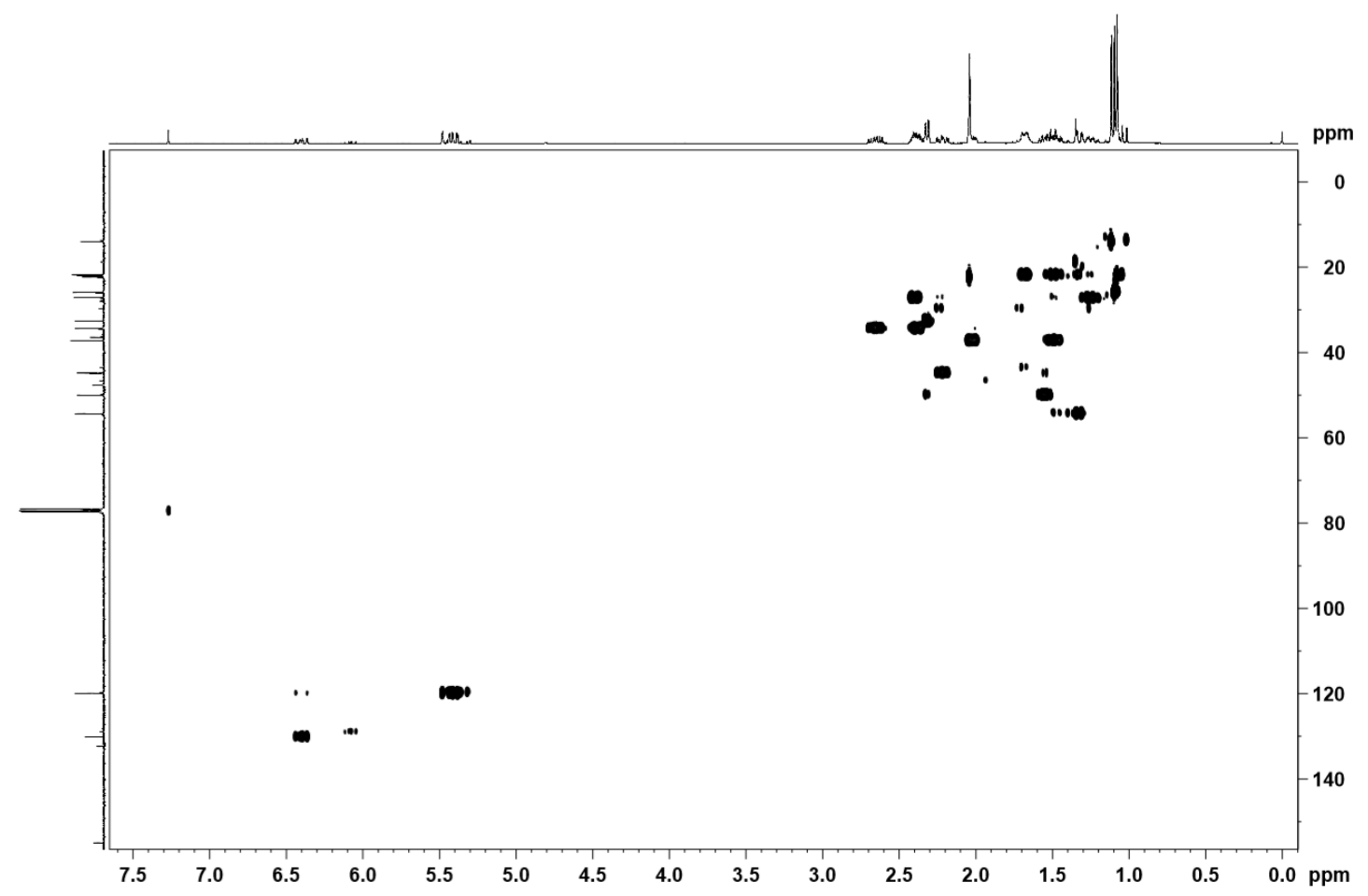


Figure S41. $\mathrm{HMBC}$ spectrum $\left(400 \mathrm{MHz}, \mathrm{CDCl}_{3}\right)$ of the compound $\mathbf{5}$

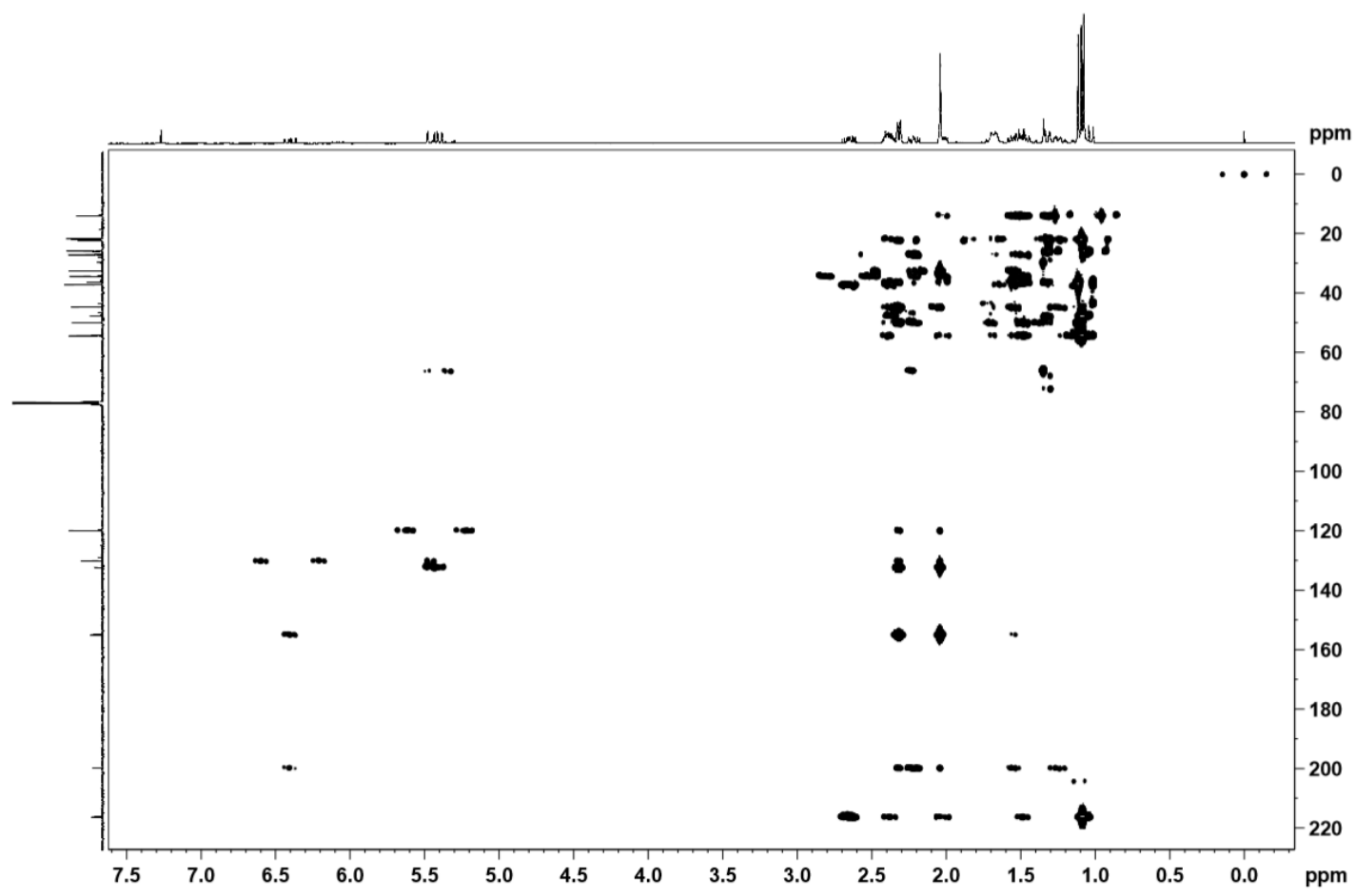

Figure S42. ${ }^{1} \mathrm{H}-{ }^{1} \mathrm{HCOSY}$ spectrum $\left(400 \mathrm{MHz}, \mathrm{CDCl}_{3}\right)$ of the compound $\mathbf{5}$

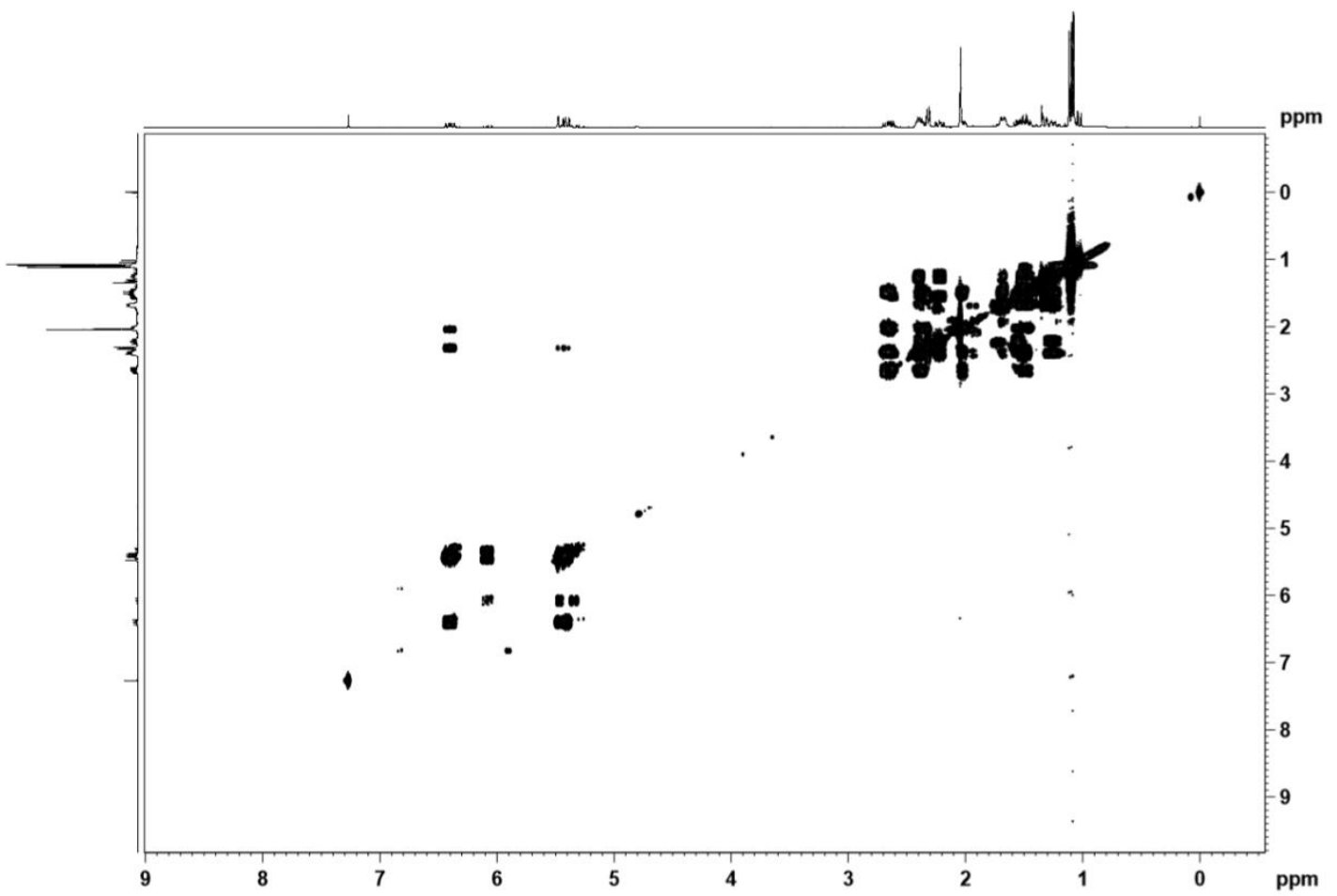


Figure S43. NOE Spectrum of the compound 5

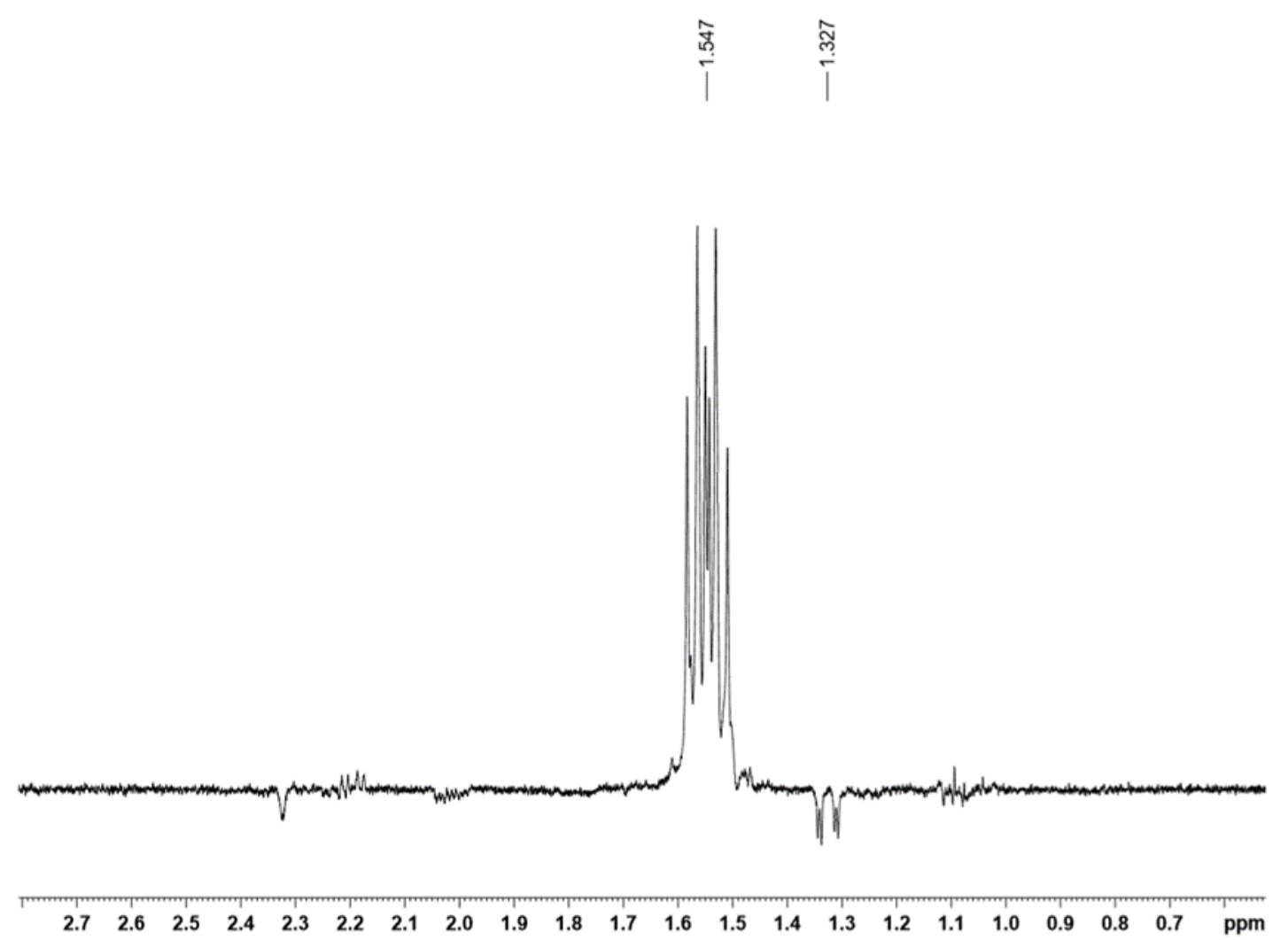

Figure S44. NOE Spectrum of the compound 5

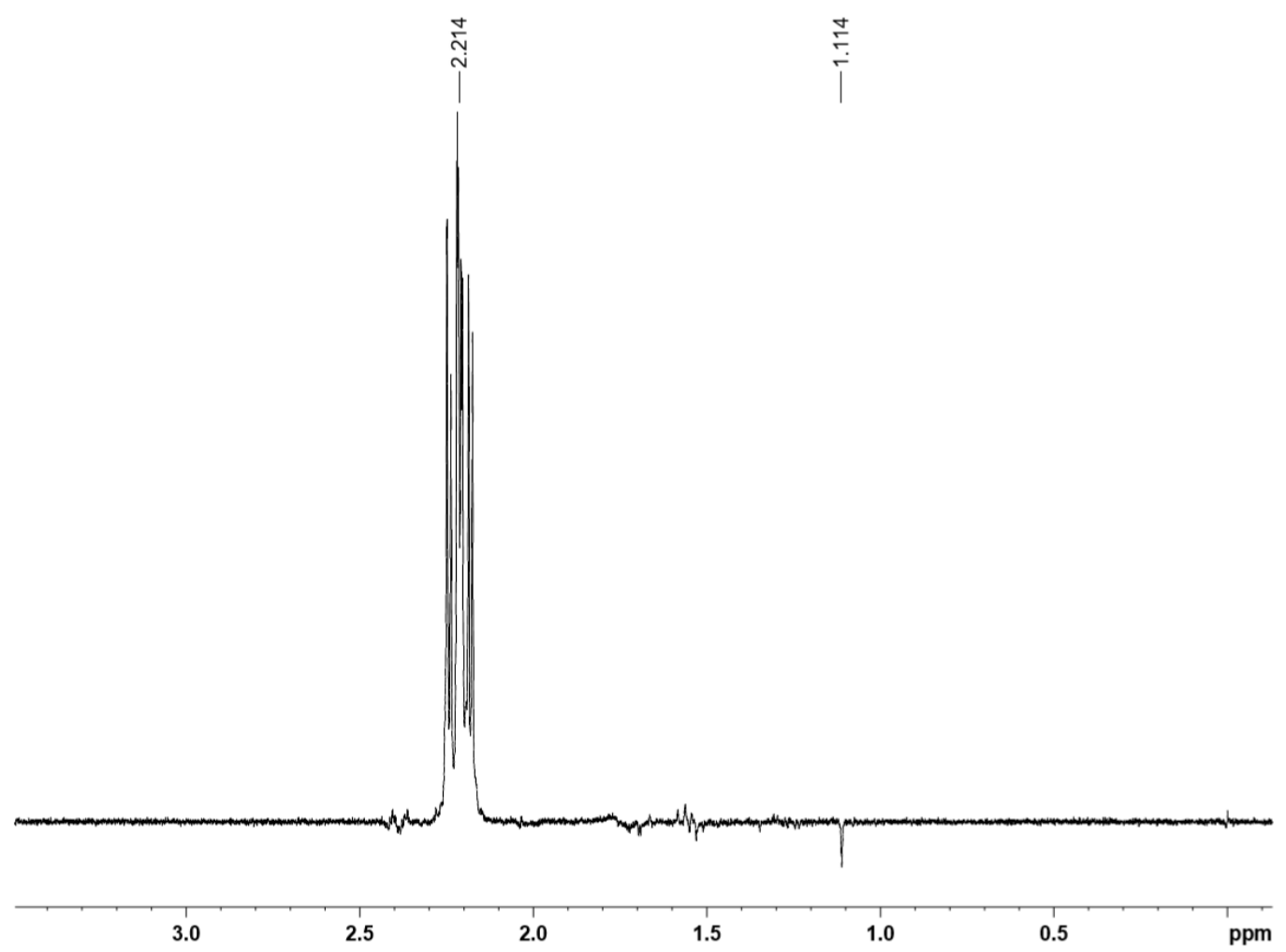


Figure S45. Optimized structures, relative energies, and Boltzmann populations of the lowest-energy conformers identified for $(5 R, 8 S, 9 S, 10 R, 13 S)-\mathbf{2}$.

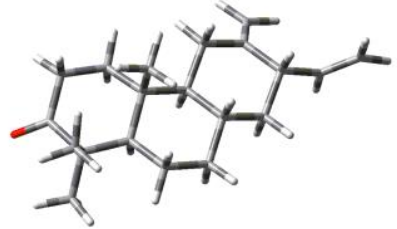

Conf1. $0.0 \mathrm{kcal} / \mathrm{mol}(79 \%)$

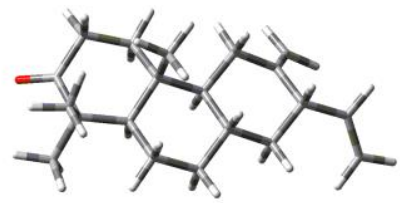

Conf2. $+1.06 \mathrm{kcal} / \mathrm{mol}(13 \%)$

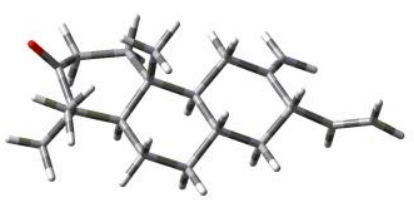

Conf3. $+1.40 \mathrm{kcal} / \mathrm{mol}(8 \%)$

Figure S46. Optimized structures, relative energies, and Boltzmann populations of the lowest-energy conformers identified for $(5 R, 8 S, 9 S, 10 R, 13 R)-2$

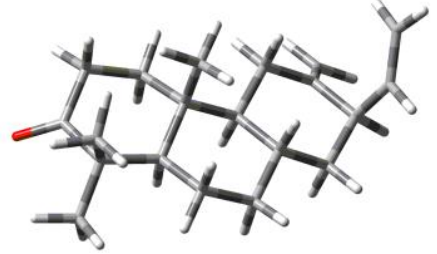

Conf1. $0.0 \mathrm{kcal} / \mathrm{mol}(44 \%)$

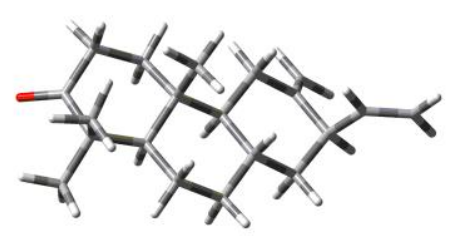

Conf2. $+0.15 \mathrm{kcal} / \mathrm{mol}(35 \%)$

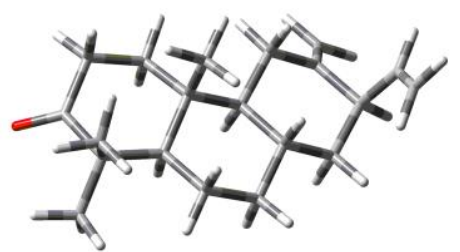

Conf3. $+0.6 \mathrm{kcal} / \mathrm{mol}(15 \%)$

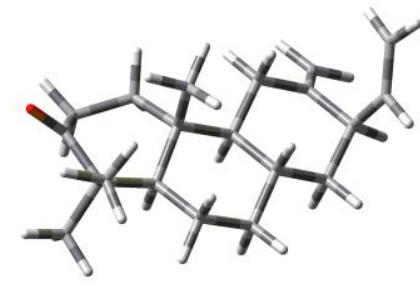

Conf4. $+1.53 \mathrm{kcal} / \mathrm{mol}(3 \%)$

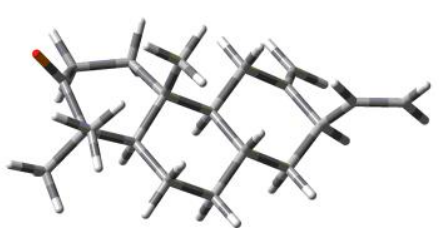

Conf5. $+1.59 \mathrm{kcal} / \mathrm{mol}(3 \%)$ 
Figure S47. Experimental and calculated vibrational dissymmetry factor (VDF) spectra

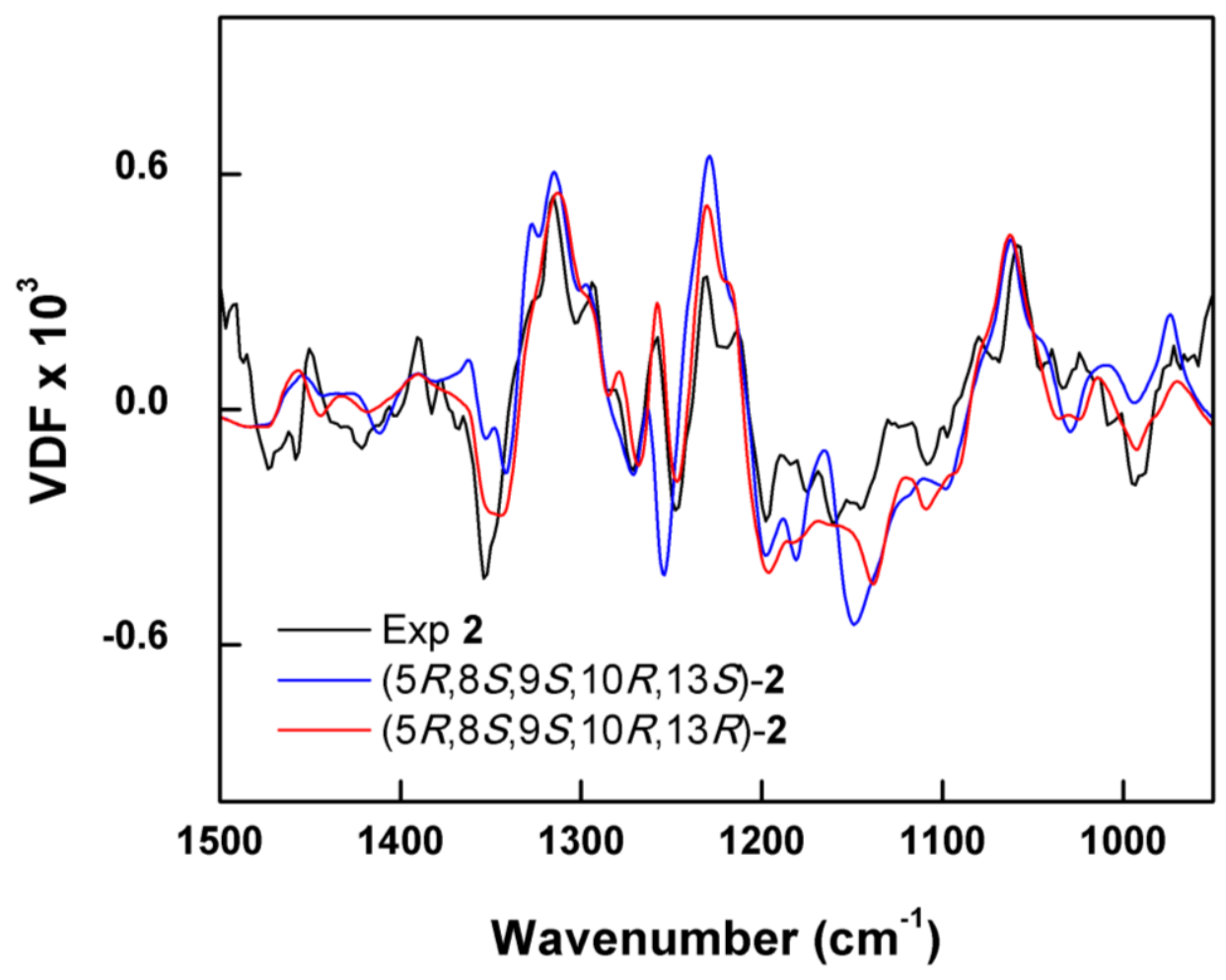

